\title{
Trends in Double Networks as Bioprintable and Injectable Hydrogel Scaffolds for Tissue Regeneration
}

Citation for published version (APA):

Aldana, A. A., Houben, S., Moroni, L., Baker, M. B., \& Pitet, L. M. (2021). Trends in Double Networks as Bioprintable and Injectable Hydrogel Scaffolds for Tissue Regeneration. ACS Biomaterial Science and Engineering, 7(9), 4077-4101. https://doi.org/10.1021/acsbiomaterials.0c01749

Document status and date:

Published: 13/09/2021

DOI:

10.1021/acsbiomaterials.0c01749

Document Version:

Publisher's PDF, also known as Version of record

Document license:

Taverne

Please check the document version of this publication:

- A submitted manuscript is the version of the article upon submission and before peer-review. There can be important differences between the submitted version and the official published version of record.

People interested in the research are advised to contact the author for the final version of the publication, or visit the DOI to the publisher's website.

- The final author version and the galley proof are versions of the publication after peer review.

- The final published version features the final layout of the paper including the volume, issue and page numbers.

Link to publication

\footnotetext{
General rights rights.

- You may freely distribute the URL identifying the publication in the public portal. please follow below link for the End User Agreement:

www.umlib.nl/taverne-license

Take down policy

If you believe that this document breaches copyright please contact us at:

repository@maastrichtuniversity.nl

providing details and we will investigate your claim.
}

Copyright and moral rights for the publications made accessible in the public portal are retained by the authors and/or other copyright owners and it is a condition of accessing publications that users recognise and abide by the legal requirements associated with these

- Users may download and print one copy of any publication from the public portal for the purpose of private study or research.

- You may not further distribute the material or use it for any profit-making activity or commercial gain

If the publication is distributed under the terms of Article $25 \mathrm{fa}$ of the Dutch Copyright Act, indicated by the "Taverne" license above, 


\section{Trends in Double Networks as Bioprintable and Injectable Hydrogel Scaffolds for Tissue Regeneration}

Ana A. Aldana, ${ }^{\dagger}$ Sofie Houben, ${ }^{\dagger}$ Lorenzo Moroni, Matthew B. Baker,* and Louis M. Pitet* $^{*}$

Cite This: ACS Biomater. Sci. Eng. 2021, 7, 4077-4101

Read Online

ACCESS | Llll Metrics \& More $\quad$ 回 Article Recommendations

ABSTRACT: Additive manufacturing and injection are essential tools in the rapidly developing field of personalized medicine and are particularly promising for applications in regenerative medicine. One of the biggest challenges in this vibrant research domain remains the processing of complex formulations with robust mechanical properties. Mimicking the native extracellular matrix associated with many tissues requires materials that have high degrees of functionality for performing the complex array of functions within the cellular environment. Furthermore, native tissues often possess outstanding mechanical properties, particularly in connective tissues. These exceptional mechanics are a challenge to emulate in their own right, especially considering the accompanying demands for additional functionality. Double-network hydrogels have emerged as strong candidates for tissue engineering because of the impressive mechanics and versatility in terms of

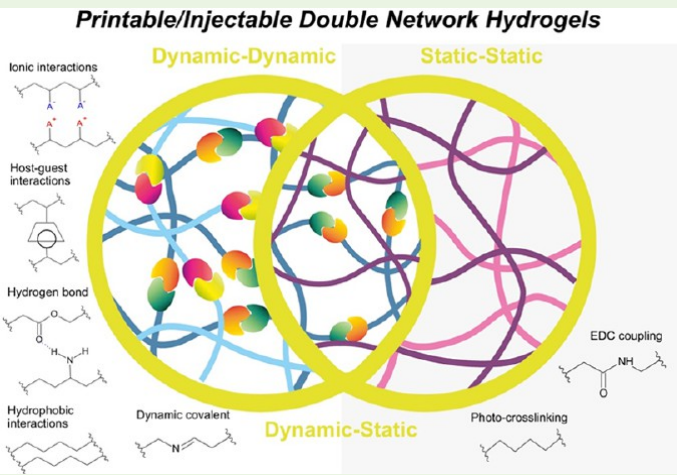
chemical makeup. Combining advances in processing (i.e., additive manufacturing and injection) with dual-network hydrogel formulations has led to an impressive collection of results, making great strides toward systems capable of addressing the demanding environment surrounding tissues while being amenable to personalized fabrication techniques. This review provides a brief summary of the most contemporary trends collected from the literature describing dual-network hydrogels being demonstrated in additive manufacturing and injectable applications.

KEYWORDS: regenerative medicine, bioprinting, biofabrication, tissue engineering, double-network hydrogels

\section{INTRODUCTION}

Advances in tissue engineering and regenerative medicine are leading us closer to the regeneration and repair of organs, soft tissue, and bone and providing improved tools to combat some of societies' most degenerative diseases. A major effort within this field is the creation of a suitable cellular environment to facilitate tissue formation and promote natural regenerative processes. Links between cellular behavior, materials properties, and soluble signals are fairly well established, and the efficacy of designed materials to steer regeneration has been shown. Yet, engineered systems remain far from the functional complexity and responsiveness of the cell's native extra-cellular matrix (ECM).

Currently, the majority of biomaterials described for tissue regeneration applications remain relatively simple, having few components and expressing basic functionality. This has largely enabled the creation of valuable structure-property relationships and fundamental knowledge that form the basis for our current understanding of these complex systems. However, biomaterials often poorly recapitulate the complex natural system. More complex materials including those with responsive, dynamic, and cell instructive components are actively being investigated in order to mimic more advanced functions of the ECM. Asking a single network to embody all the functions of the ECM is formidable. As the field moves toward more complex biomaterials, hydrogels comprised of multiple networks have emerged as a powerful tool for attaining the necessary physical properties associated with native tissues. Furthermore, these dual-network hydrogels allow a great deal of versatility with regard to engineering of specific properties into individual networks.

Additive manufacturing of biomaterials is an attractive way to create living $3 \mathrm{D}$ constructs with custom placement of bioactive agents and cells. These collective biofabrication techniques have shown great promise toward ultimately allowing the reconstruction of life-like tissue models and recreation of the 3D complexity of organs. The properties required of a printable bioink are demanding; they must be processable, biocompatible, and possess functional tissue

Special Issue: Advanced Biomedical Hydrogels

Received: December 17, 2020

Accepted: February 5, 2021

Published: February 19, 2021

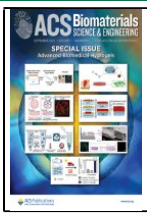


regeneration properties. Likewise, injectable hydrogels for tissue regeneration have similar requirements, but instead of needing to keep shape on a platform, they must facilitate hydrogel formation on demand (i.e., in vivo). In both areas (i.e., printing and injection), dual-network systems provide many advantages over single-network counterparts.

The broad challenge in the development of tissueengineered biomaterials is to mimic the microenvironment that provides complex site-specific combination of biochemical and mechanical cues to influence cell adhesion, proliferation, and differentiation during maturation processes. ${ }^{1,2}$ The ECM is an interpenetrating network composed of proteoglycans and fibrous assemblies of proteins. The multiple functions of ECM include mechanical and structural support of cells, spatiotemporal growth factor presentation, traction and movement, and the ability to remodel in response to a cell or external stimuli. Mirroring the properties of the ECM remains a coveted target in biomaterials design, which is relevant for regenerative medicine and tissue engineering. The aim of these fields is to create therapies to replace or regenerate human cells, tissues, and organs toward the restoration of injured, damaged, or aged tissues and organs. ${ }^{3,4}$ Therefore, the creation of controllable materials, with cell signaling, delivery of bioactive molecules at controlled rates, and tunable and responsive mechanical properties, is needed to restore or establish the normal function of tissues/organs.

In the past decades, various ECM-inspired three-dimensional (3D) scaffolds have been investigated, including electrospun meshes, ${ }^{5-8}$ patterned surfaces, ${ }^{5,7,9,10}$ and additive manufactured scaffolds, ${ }^{4,11-15}$ with hydrogels being among the most promising ECM replacements. Hydrogels typically comprise macromolecular three-dimensional networks with a high water content. As previously mentioned, the natural ECM is a dynamic interpenetrating network hydrogel. Following the progress in polymer chemistry, synthetic chemistry, and supramolecular chemistry, the design of hydrogels networks has advanced from covalent and static networks to instructive, stimuli-responsive, biodegradable and dynamic networks. These complex and dynamic systems that mimic ECM functions could recreate properties, as for example cell mediated remodeling, cell adhesion, strain-stiffening and viscoelasticity, through the incorporation of cleavable bonds, reversible bonds, supramolecular self-assembly, or flexible polymer backbones.

In this review, we will cover recent trends in double-network hydrogels as bioprintable and injectable scaffolds for tissue regeneration. We first introduce the concepts double-network hydrogels, bioprinting, and injectability, and provide some guidelines when designing hydrogels for such applications. Several examples from the recent literature are then showcased where double networks have been used, or are well-poised for use, in bioprinting and injectable applications. The chemical design of the networks constitutes an important focus. As such, the examples are categorized by the nature of the individualnetwork cross-linking: static vs dynamic. Lastly, we provide insights into the future directions of the field.

1.1. Double Networks. The search for biomaterials to substitute biological tissues and structures has driven the field of hydrogels into several directions. Many strategies have been developed to improve hydrogel biochemical and mechanical properties. Among these strategies is the principle of doublenetwork (DN) hydrogels, originating in 2003 as a method to obtain strong and stiff hydrogels. ${ }^{16}$ This discovery led to a rapid expansion and discovery phase, especially in the field of tissue engineering, as a solution to the often brittle or weak single-network hydrogels conventionally used. In combination with recent advances in bioprinting technologies, the printing and injection of tough constructs to be used for tissue regeneration has advanced; however, several challenges persist with these applications. Before addressing these challenges, a brief overview of the mechanisms behind double-network hydrogels is provided.

Gong and co-workers reported the first DN hydrogel made of two synthetic polymer networks: sparsely cross-linked poly(acrylamide) (PAAm) and densely cross-linked anionic poly(2-acrylamido-2-methylpropanesulfonic acid) (PAMPS). ${ }^{16}$ This combination led to high strength gels that break at a stress of up to $17.2 \mathrm{MPa}$ and a compressive strain up to $92 \%$. Subsequent investigations elucidated a fundamental relationship between the networks. A defining structure/property relationship of $\mathrm{DN}$ hydrogels is the use of two different polymer networks with contrasting network density; the key to obtaining strong gels has been directly attributed to the ratio of these networks and the degree of cross-linking.

Of note, there is some confusion in the literature as to terminology around the combination of hydrogel networks to make a dual-network system. In this review, we will refer to all dual-network systems as interpenetrating networks (IPN) and reserve the nomenclature of double network (DN) for IPNs exhibiting improved mechanical properties. IPN hydrogels generally do not show any improvement in mechanical properties compared to their separate single networks. ${ }^{16,17}$ DN hydrogels can be considered a separate class of IPNs: all double-network hydrogels are interpenetrating networks, but not all interpenetrating networks are double-network hydrogels. Despite differences in performance and nomenclature, IPNs provide distinct benefits beyond mechanical toughness when designing biomedical materials.

DN hydrogels typically show an enhanced/optimal mechanical strength at a certain ratio of the two networks. Deviating from this ratio leads to a decrease in toughness. The mechanical strength can also be tuned with the cross-link density; the best results are often obtained when one network has a much higher cross-linking density than the other. Two networks with opposing mechanical properties are most often used, with one network being flexible and the other being brittle. The flexible network, when cross-linked sparsely, imparts extensibility. The brittle network, often a densely cross-linked polyelectrolyte, will be relatively stiff. Under large deformations, the brittle network will dissipate energy by the fracture of its cross-links, whereas the flexible network remains intact and typically allows the hydrogel to recover from strain to an extent. The combination of these two types of networks therefore leads to enhanced mechanical properties, wherein the resulting gel embodies attributes from different types of mechanical response. ${ }^{18}$

Double-network hydrogels can be categorized by polymer type, mechanical performance, or cross-linking type. In this review, we will focus on the type of cross-linking used to form the two networks. With the energy dissipation being the key defining mechanism of double networks, two different types of cross-linking are often present. The most straightforward way of describing cross-linking is by making a distinction between static $^{19}$ and dynamic (dynamic covalent or noncovalent) crosslinking. We take this approach in categorization, as the crosslinking character has profound influence on the resulting 


\section{BIOPRINTING}
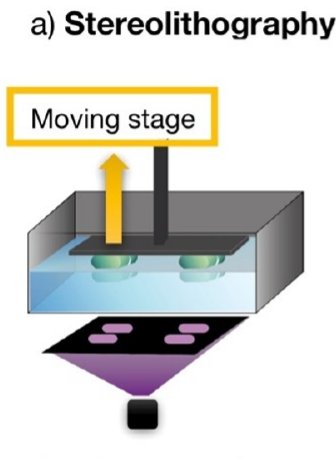

Light Projection System

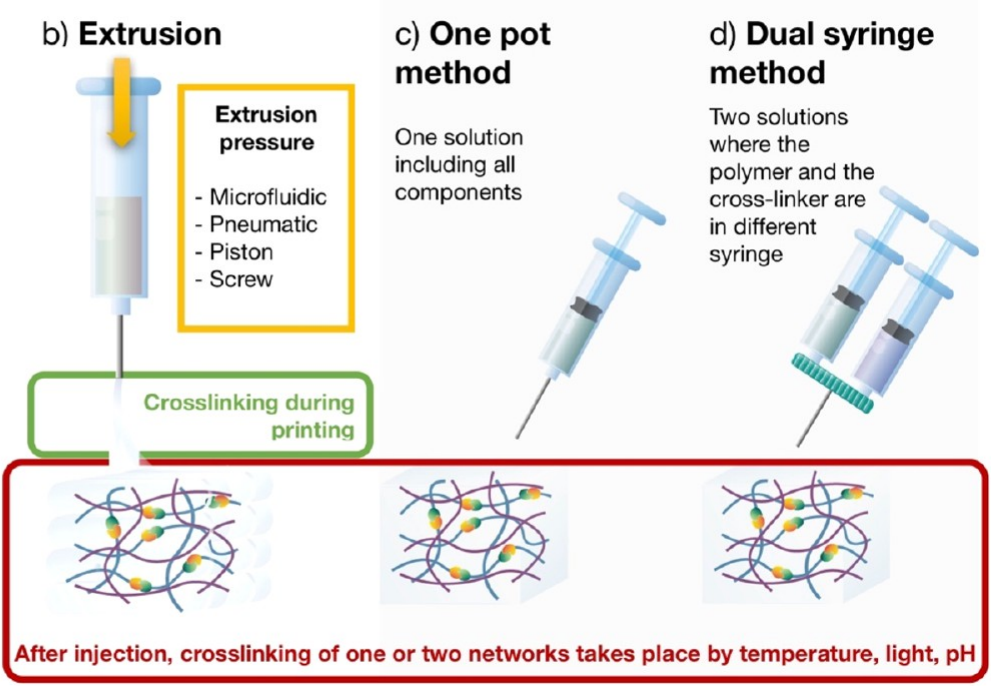

Figure 1. Schematic overview of the processing and delivery methods covered in this review: 3D bioprinting and injection of double-network hydrogel scaffolds, with the most commonly employed strategies highlighted. (a) Stereolithography and (b) extrusion-based printing technologies and (c) one-pot (single syringe) and (d) dual syringe methods of injection.

behavior of the gels. The incorporation of various network junctions (e.g., covalent bonding, ionic bonding, hydrogen bonding) is used as a tool for modulating the strength or responsiveness of the scaffolds. With several strategies being well-developed for generating DN hydrogels with exceptional mechanical properties, the next major challenge is the effective delivery of such scaffolds. This review covers recent advances in $3 \mathrm{D}$ bioprinting and injectability of DN hydrogel scaffolds targeting applications in tissue engineering and regenerative medicine (Figure 1). Special attention is paid to the chemical nature of the networks and the corresponding link to the resulting properties.

1.2. Bioprinting. Additive manufacturing (e.g., 3D printing) has fundamentally altered the way materials constructs are designed and fabricated, enabling rapid and reproducible creation of customized objects. ${ }^{20}$ In the biomedical field, emerging biofabrication tools ${ }^{3,21,22}$ have changed the approach to tissue engineering by allowing the creation of complex $3 \mathrm{D}$ objects, and additive manufacturing more specifically facilitates rapid prototyping and streamlining of systematic variations in manufacturing processes. ${ }^{23,24}$ Using suitable printing technologies with a processable and biocompatible material platform facilitates the creation of customizable implants, specific to a patient's form factor or tailored to the tissue environment. Furthermore, by introducing cells during the fabrication process, one can create highly complex and user-defined living constructs for cell-based tissue engineering in vivo and tissue models in vitro. Bioprinting of cell-laden hydrogel scaffolds enables the spatial organization or specific compartmentalization of different cell types, ultimately mimicking the orientation of native tissues. These possibilities deliver with them the prospect of complex organ regeneration in the future. Recent work has shown the complexity and function afforded by additive manufacturing via the creation of anatomically correct heart components, ${ }^{25}$ and a functional alveolar and vascular network ${ }^{26}$ from simple materials and fabrication processes. In spite of the potential of 3D bioprinting, the recreation of functional organs or translatable constructs remains beyond reach. ${ }^{4,27}$ Notably, there are a limited number of materials options in this area, attributed to the strict requirements for both processability and tissue formation. 28,29

Various methods exist for additive manufacturing of biomaterials both with and without cells, which often require different conditions. For clarification on nomenclature and comprehensive reviews of the various techniques, we direct the reader elsewhere. ${ }^{3,22,30}$ Herein, we will briefly cover the major classes of additive manufacturing that have shown applicability to double-network hydrogels, namely, extrusion-based printing and digital light processing (DLP). This is not intended to imply that other techniques are not suitable or that further developments will not enable utilization in the future. On the contrary, novel processing techniques for interpenetrating networks (IPNs) and double networks promise to be a rich area of exploration.

Currently, extrusion-based printing of hydrogels remains one of the most widely used and accessible methods for 3D biofabrication, ${ }^{31}$ in large part due to the number of commercial options on the market. ${ }^{32}$ Extrusion-based printing generally relies on the processing of the hydrogel through a syringe and needle via pressure, a piston, or a rotating screw. The size of features produced by extrusion techniques is limited to hundreds of micrometers because of the needle size and material viscosity needed to produce a filament.

Two of the earliest examples of fabrication utilizing a printing technique and hydrogels involved the use of hydrogels as a 3D "paper" for the printing of spheroids, ${ }^{33,34}$ and stereolithography (SLA) for the encapsulation of cells in acrylate based networks. ${ }^{35}$ Although light-based polymerization was one of the first techniques utilized for printing with cells, initial fabrication methods of SLA were simply not easily scalable when printing voxel by voxel. With the recent emergence of stepwise and continuous light-based projection fabrication systems, ${ }^{36}$ commonly referred to as DLP, rapid production of relatively large objects is readily employed in many laboratories. In these techniques, a $2 \mathrm{D}$ sheet of light 
polymerizes a thin layer of the photoresin and the stepwise (or continuous) movement of the stage allows the creation of a 3D object in slices. DLP-based printing techniques are limited to photopolymerizable and low-viscosity resins. The size of features is limited by the speed and scattering of light, with some formulations and systems being able to approach the tens of micrometers in resolution. DLP-based systems can also fabricate more complex geometries (like gyroids), which are significantly more challenging to obtain via extrusion-based additive manufacturing.

Although extrusion and DLP represent two of the most widely used techniques, several more exotic techniques exist, which are amenable to the use of double-network hydrogels in biofabrication. Gel-in-gel printing techniques like FRESH ${ }^{37}$ and Ghost writing ${ }^{38}$ allow for the creation of high-resolution features by depositing soft inks into a self-healing supportive bath. Advanced variants of extrusion bioprinting, these modifications facilitate the use and overcome limitations of softer materials. New techniques like holographic ${ }^{39}$ and volumetric ${ }^{40}$ printing techniques also expand the capabilities of light-based resin additive manufacturing. Although these techniques allow more intricate and faster fabrication, their complexity and novelty has thus far precluded widespread adoption. As more advanced techniques witness broader implementation, their expansion from single-network to double-network hydrogel printing will undoubtedly be an active area of exploration.

Hydrogel Development. Of note, there are two main methods for utilizing hydrogels in additive manufacturing: (1) the use of hydrogels without cells, wherein the material is referred to as a hydrogel or biomaterial ink, and (2) the use of hydrogels with encapsulated cells during the fabrication process, wherein the formulation and material is referred to as a bioink. ${ }^{41}$ Naturally, both types of hydrogels need to ultimately support cell viability and tissue growth, yet the bioink formulations must also maintain cell viability during the printing process. Several comprehensive reviews have been published on the development of hydrogel inks generally, ${ }^{29,41-45}$ and we direct the reader to these manuscripts for further insight into historical development.

Extrusion-based additive manufacturing often relies on shear thinning properties of hydrogels or hydrogel precursors, followed by rapid gelation upon deposition. The shear thinning allows for easier processing and can help protect cells from shear stress ${ }^{46}$ in bioinks, whereas the rapid gelation is needed to prevent material creep and loss of shape fidelity. Gelation can often be triggered via ionotropic gelation or photopolymerization, ${ }^{47,48}$ yet movements toward dynamic inks ${ }^{11}$ via dynamic-covalent ${ }^{49}$ and supramolecular chemistry ${ }^{38}$ can facilitate autonomous solidification after extrusion.

Light-based printing requires a photopolymerizable unit within the hydrogel resin formulation in order to initiate polymerization and/or cross-linking reactions. Examples in the literature are dominated by (meth)acrylate ${ }^{50}$ (or double bond $)^{51}$ based systems, with recent emergence of thiol-enebased $^{48}$ cross-linking, among several other techniques. Notably, most UV-curable resins consist of a photopolymerizable unit (to form a network), a reactive diluent (to modify viscosity), a photoinitiator (to initiate polymerization), and a photoabsorber (to limit stray light). ${ }^{45}$ Each component plays a crucial role, and systematic optimization is key for printing performance in a given application.
1.3. Injectability. Injectable hydrogels must be injected, or extruded via a syringe needle, similar to the processing of extrusion-based additive manufacturing (vide supra). Injecting hydrogel formulations facilitates localized, noninvasive delivery of tissue support scaffolds. This enables minimally invasive procedures to replace implantation for a wide range of applications including stem-cell based therapy, ${ }^{52}$ cancer therapy, ${ }^{53,54}$ wound dressings, ${ }^{55}$ minimally invasive surgery, ${ }^{56}$ and drug delivery. ${ }^{57}$ For tissue regeneration applications, these injectable scaffolds typically comprise materials, cells, and soluble growth factors to enable tissue formation and has shown advantages in areas including cardiovascular, ${ }^{58}$ cartilage, $^{59}$ and bone tissue engineering. ${ }^{60}$ Notably, the use of stem-cell-based therapies with injectable gels has been shown to increase the regenerative capacity of the treatment, ${ }^{52}$ with clear examples in improving the lifetime of adiposederived stem cells during the repair of ischemic limbs in mice, ${ }^{61}$ and the integration of retinal stem cell therapy leading to better sight in mice. ${ }^{62}$

There are mainly two methods for injection of hydrogels: one pot (Figure 1c) and dual syringe (Figure 1d). The selection of each method depends on the cross-linking rate and chemical nature of the cross-links. In the first method, only one hydrogel precursor solution is prepared and then the crosslinking takes place in situ by external stimuli (e.g., light irradiation, temperature, $\mathrm{pH}$ ). In contrast, dual syringes are useful for rapid cross-linking reactions (with or without external stimuli). Polymers and/or cross-linkers (i.e., hydrogel precursor solutions) are prepared in separate syringes. The solutions are mixed in situ, with cross-linking occurring rapidly enough to maintain shape in the resulting hydrogel.

Shear-thinning hydrogels also improve cell-viability postinjection in self-healing hydrogels, as in the case of extrusionbased printing (vide infra). ${ }^{63}$ Two major differences exist in injectable hydrogels compared to bioprintable hydrogels: (1) injection needs to be facilitated in the operating theater usually via manual pressure (lower viscosity) and (2) the formation of the final construct takes place in vivo. Notably, the requirement to form the network in vivo leads more often to the use of autonomous (or in situ) cross-linking methods for injectable hydrogel formulations.

These brief discussions of the processing/delivery techniques covered in this review set the basis for the material requirements. The remaining sections highlight examples of DN hydrogel scaffolds within this context. The first main section covers examples of $\mathrm{DN}$ gels used in various printing and biofabrication applications, wherein the examples are further divided into categories according to the cross-linking chemistry. The next section covers examples in which injectable DN gels was the main focus. Finally, some guidance for the future is provided with the insight gathered from the examples presented.

\section{DN AS BIOPRINTABLE HYDROGELS}

The biochemical and mechanical properties of a hydrogel are critical for tissue engineering. Biocompatibility, mechanical properties, cell-matrix interactions, and diffusion of nutrients must all be taken into account to develop successful hydrogel matrices for cell growth and tissue formation. In addition, when developing hydrogels for additive manufacturing, the material must provide suitable performance before, during, and after fabrication-all while maintaining a habitable environment for cells. In this work we focus on extrusion bioprinting, as this 
Table 1. Summary of Dual-Network Hydrogels Used for 3D Printing ${ }^{a}$

\begin{tabular}{|c|c|c|}
\hline $\begin{array}{l}\text { polymer } \\
\text { source }\end{array}$ & polymer networks & cells \\
\hline $\begin{array}{l}\text { synthetic/ } \\
\text { synthetic }\end{array}$ & $\begin{array}{l}\text { 1- PAMPS (ionic) } \\
\text { 2- PAAm (covalent) }\end{array}$ & Dynamic/Static Netw \\
\hline $\begin{array}{l}\text { natural/ } \\
\text { synthetic }\end{array}$ & $\begin{array}{l}\text { 1-alginate (ionic, } \mathrm{CaCl} 2 \text { ) } \\
\text { 2-PEGDA (covalent) }\end{array}$ & $\begin{array}{l}\text { hMSC, human embryonic kidne } \\
293 \text { cells }\end{array}$ \\
\hline $\begin{array}{l}\text { natural/ } \\
\text { synthetic }\end{array}$ & $\begin{array}{l}\text { 1-alginate (ionic, } \mathrm{CaCl}_{2} \text { ) } \\
\text { 2-GelMA (covalent) }\end{array}$ & $\begin{array}{l}\text { NIH } 3 \text { T3 mouse fibroblasts }(2 \\
\text { h) }\end{array}$ \\
\hline $\begin{array}{l}\text { natural/ } \\
\text { synthetic }\end{array}$ & $\begin{array}{l}\text { 1-alginate (ionic, } \mathrm{CaCl}_{2} \text { ) } \\
\text { 2-acrylamide (covalent, MBAA) }\end{array}$ & $\begin{array}{l}\text { human umbilical vein endotheli } \\
\text { cells ( } 3 \text { days) }\end{array}$ \\
\hline & & $\begin{array}{l}\text { L929 cells and rat aortic } \\
\text { endothelial cells (RAOEC) }\end{array}$ \\
\hline $\begin{array}{l}\text { natural/ } \\
\text { synthetic }\end{array}$ & $\begin{array}{l}\text { 1-alginate (ionic, } \mathrm{CaCl}_{2} \text { ) } \\
\text { 2- NiPAAm (covalent, MBAA) }\end{array}$ & \\
\hline $\begin{array}{l}\text { natural/ } \\
\text { synthetic }\end{array}$ & $\begin{array}{l}\left.\text { 1-alginate (ionic, } \mathrm{CaCO}_{3}+\mathrm{GDL}\right) \\
\text { 2-P(AAm) (covalent, MBAA) Or P } \\
\text { (NiPAAm) Or P(HEA) Or P } \\
\text { (NiPAAm-co-HEA) }\end{array}$ & \\
\hline $\begin{array}{l}\text { natural/ } \\
\text { synthetic }\end{array}$ & $\begin{array}{l}\text { alginate (ionic, } \mathrm{CaCl}_{2} \text { ) } \\
\text { 2-PEOXA- peptide (covalent, enzymatic) }\end{array}$ & $\begin{array}{l}\text { Human auricular chondrocytes } \\
\text { (hACs), } 14 \text { days }\end{array}$ \\
\hline $\begin{array}{l}\text { natural/ } \\
\text { natural }\end{array}$ & 1-HA-catechol (covalent) & HUVEC, 14 days \\
\hline $\begin{array}{l}\text { natural/ } \\
\text { natural }\end{array}$ & $\begin{array}{l}\text { 2-alginate (ionic, } \mathrm{CaCl}_{2} \text { ) } \\
\text { 1-alginate (ionic, } \mathrm{CaCl} 2 \text { ) } \\
\text { 2-gelatin (covalent, glutaraldehyde) }\end{array}$ & \\
\hline $\begin{array}{l}\text { natural/ } \\
\text { synthetic }\end{array}$ & $\begin{array}{l}\text { 1-K-carrageenan (ionic) } \\
\text { 2-AAm (covalent, MBAA) }\end{array}$ & - \\
\hline $\begin{array}{l}\text { natural/ } \\
\text { synthetic }\end{array}$ & $\begin{array}{l}\text { 1-K-carrageenan (ionic) } \\
\text { 2-GelMA (covalent) }\end{array}$ & - \\
\hline
\end{tabular}

hMSCs, 60 days other components: laponite key details cast: tensile strength $>1.6 \mathrm{MPa}$, fracture energy $>8000 \mathrm{~J} \mathrm{~m}^{2-}$ printed: tensile strength $0.6 \mathrm{MPa}$, fracture energy $>5000 \mathrm{~J} \mathrm{~m}^{2-}$

other components: laponite cast: $400 \%$ elongation, tensile strength $200 \mathrm{kPa}$, fracture energy $1500 \mathrm{~J} \mathrm{~m}^{-2}$

printed: $300 \%$ elongation, resolution $\pm 500 \mu \mathrm{m}$

other components: Carbopol gel as structural support printed (tubular constructs) $E=25 \mathrm{kPa}$, compression strength $0.07 \mathrm{MPa}, 70-140 \mu \mathrm{m}$ filament diameter mechanical properties of DN exceed those of SNs

printing resolution $+-150 \mu \mathrm{m}$

printed: $E=15-55 \mathrm{kPa}$

other components: ethylene glycol

printed: $300 \%$ elongation, work of extension $260 \mathrm{~kJ} \mathrm{~m}^{-3}$, tensile strength $170 \mathrm{kPa}, E=66 \mathrm{kPa}$

cast: $900 \%$ elongation, tensile strength $220 \mathrm{kPa}$

other components: laponite

other components: hypoxyapatite, glucose oxidase, catalase cast: compressive modulus $7.16 \mathrm{MPa}$, storage modulus 32, $960 \mathrm{~Pa}$

other components: bacterial cellulose

$E=0.5 \mathrm{MPa}$

application: artificial tubular grafts

other components: alginate-graphene oxide

printed: tensile strength $300 \mathrm{kPa}, 2400 \%$ elongation

cast: tensile strength $800 \mathrm{kPa}, 3250 \%$ elongation

mechanical properties of DN exceed those of SNs

other components: agar (dynamic, H-bonding)

printed: tensile strength $1 \mathrm{MPa}, E=870 \mathrm{kPa}, 230 \%$ elongation

application: cartilage tissue engineering

printed: tensile strength0.05 $\mathrm{MPa}$, strain $50 \%$ (at $20{ }^{\circ} \mathrm{C}$ )

mechanical properties of both cast and printed hydrogels measured for all compositions

other components: cellulose nanofibrils (CNFs)

cast: compressive modulus $30 \mathrm{kPa}$, printing resolution $410 \mu \mathrm{m}$

mechanical properties of DN exceed those of SNs

cast: tensile strength $0.1-1.2 \mathrm{MPa}$, elongation $400-75 \%$, compression modulus up to $300 \mathrm{kPa}$, toughness up to $461 \mathrm{~kJ} \mathrm{~m}^{-3}$

mechanical properties of DN exceed those of SNs

other components: cellulose nanocrystals

pore size of printed hydrogel $80-2125 \mu \mathrm{m}$

no mechanical testing

cast: fracture energy $6150 \mathrm{~J} \mathrm{~m}^{-2}$, elongation $2000 \%$, tensile strength $550 \mathrm{kPa}, E=100 \mathrm{kPa}$

printed: compressive strain $90 \%$

mechanical properties of DN exceed those of SNs

other components: nanosilicates

printed: compressive modulus $70 \mathrm{kPa}$, pore diameter

$20-50 \mu \mathrm{m}$

mechanical properties of DN exceed those of SNs

other components: nanosilicates

printed: compression modulus $150 \mathrm{kPa}$, toughness $100 \mathrm{~kJ} \mathrm{~m}^{-2}$

application bone tissue reconstruction 


\section{Table 1. continued}

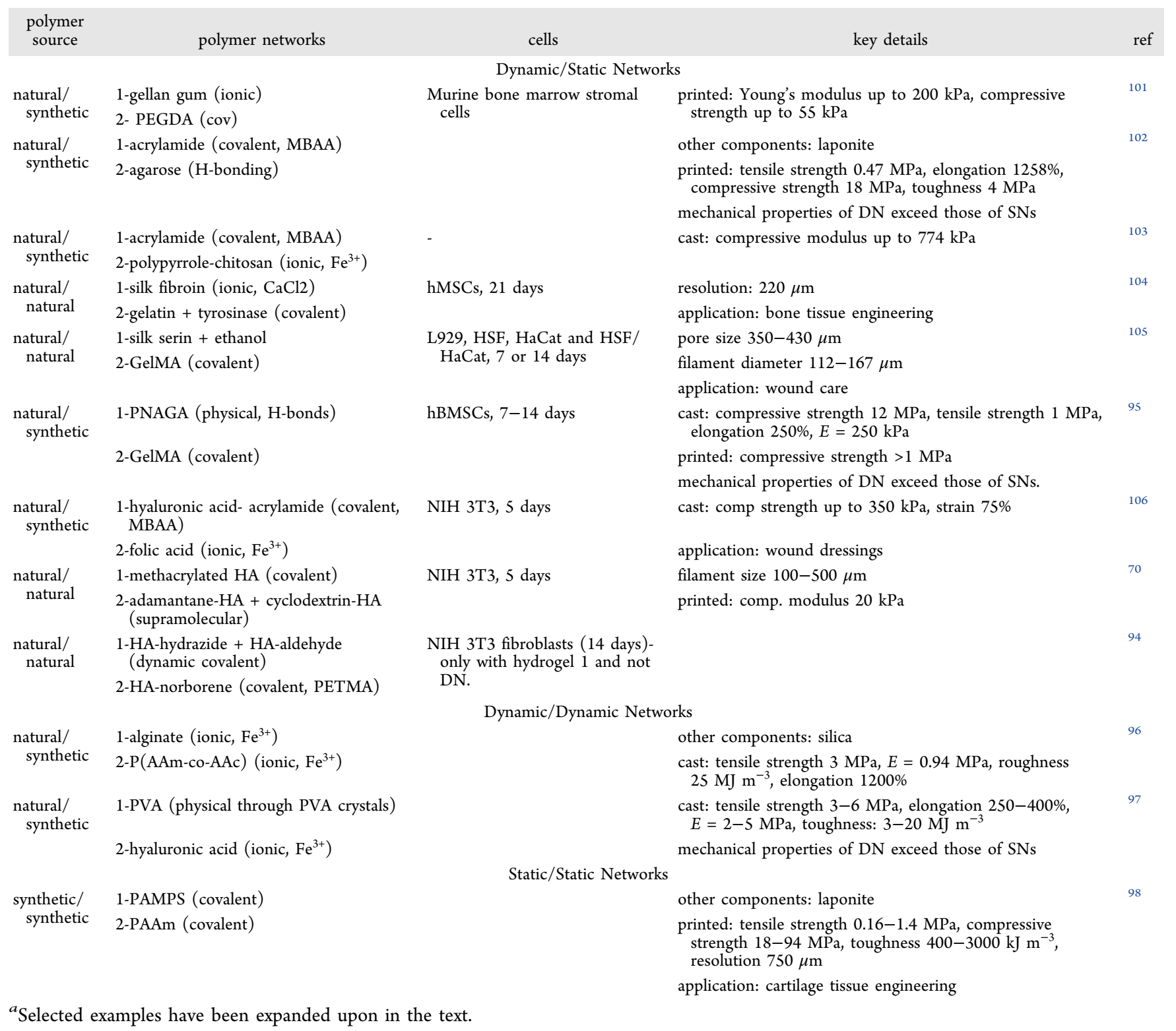

is a very accessible technique and the most used approach for printing DN hydrogels.

When considering hydrogels for extrusion bioprinting, not only the properties of the final printed structure are important. The pregel solution (in this case used as a bioink) also needs to meet certain rheological requirements. ${ }^{29,64} \mathrm{~A}$ bioink solution is initially at rest and has a relatively high viscosity. Upon application of an external force, the viscosity should decrease to ensure that the solution flows and is subsequently extruded from the nozzle. After extrusion, the viscosity should increase again for structural integrity. Evaluation of a potential bioink for its shear-thinning behavior is therefore critical. Increasing viscosity generally leads to a higher printing fidelity; however, high viscosity will also lead to deleterious shear stress for cells during extrusion. ${ }^{46,65}$ These considerations significantly narrow the scope for the physical properties of hydrogels for application in $3 \mathrm{D}$ printing.

Bioinks are often designed to gel instantaneously by making use of a fast polymerization of (meth)acrylates. For instance, a photo initiator can induce immediate curing of a bioink upon deposition, leading to strong filaments and precluding collapse of the printed structure. However, covalent cross-linking typically impedes processability, needs to be controlled to prevent blocking of the printing nozzle, and often results in a static hydrogel with nondegradable kinetic chains from the polymerization. Therefore, the focus has been shifted to using reversible cross-linking such as dynamic covalent bonds, ionic interactions, supramolecular interactions, and hydrogen bonds. ${ }^{11}$ Mild conditions are suitable for cross-linking, and these reversible interactions generally possess self-healing ${ }^{66,67}$ and shear-thinning properties. Upon extrusion, these dynamic gels undergo a gel-sol transition, and after deposition, the cross-links recombine to renew the network. Shear thinning of reversible bonds has been shown to increase cell viability during printing. ${ }^{68}$ Bioinks with supramolecular, ${ }^{38}$ dynamic covalent, $^{49}$ and electrostatic interactions have all been successfully implemented. ${ }^{69}$ Many double-network hydrogels make use of reversible cross-linking as the energy dissipation mechanism responsible for their enhanced toughness and are consequently readily amenable to printing applications. For 

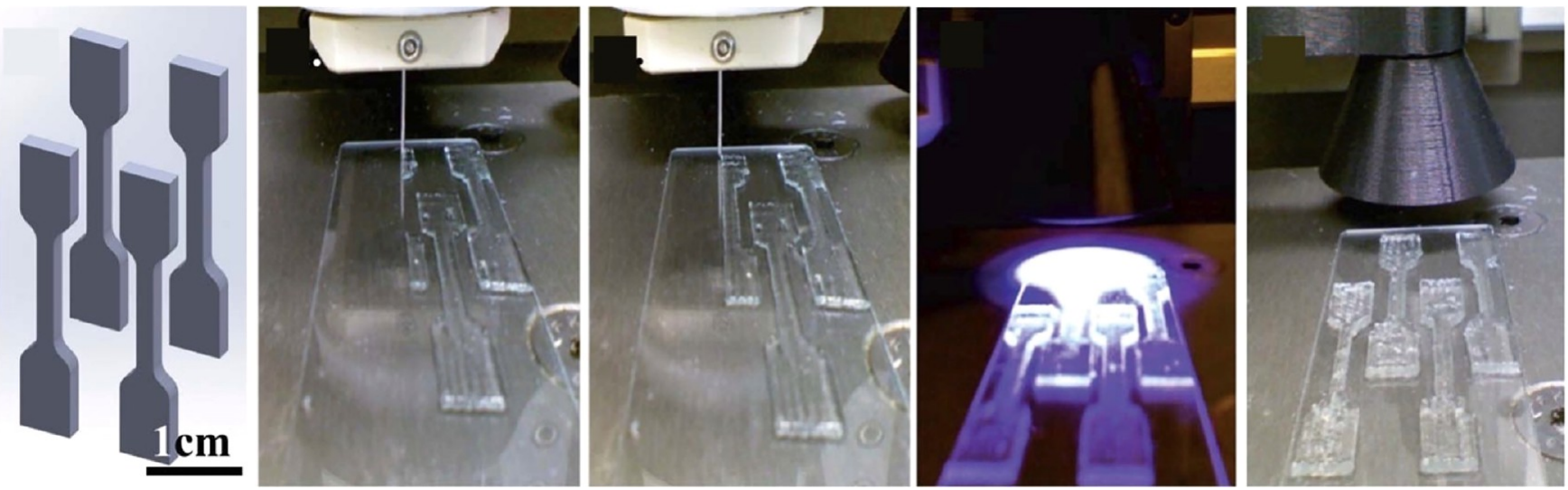

Figure 2. Extrusion printing of Ca-Alg/PAAm DN hydrogels into tensile bars followed by curing with UV light. Adapted and reproduced with permission from ref 74. Copyright 2013 Royal Society of Chemistry.

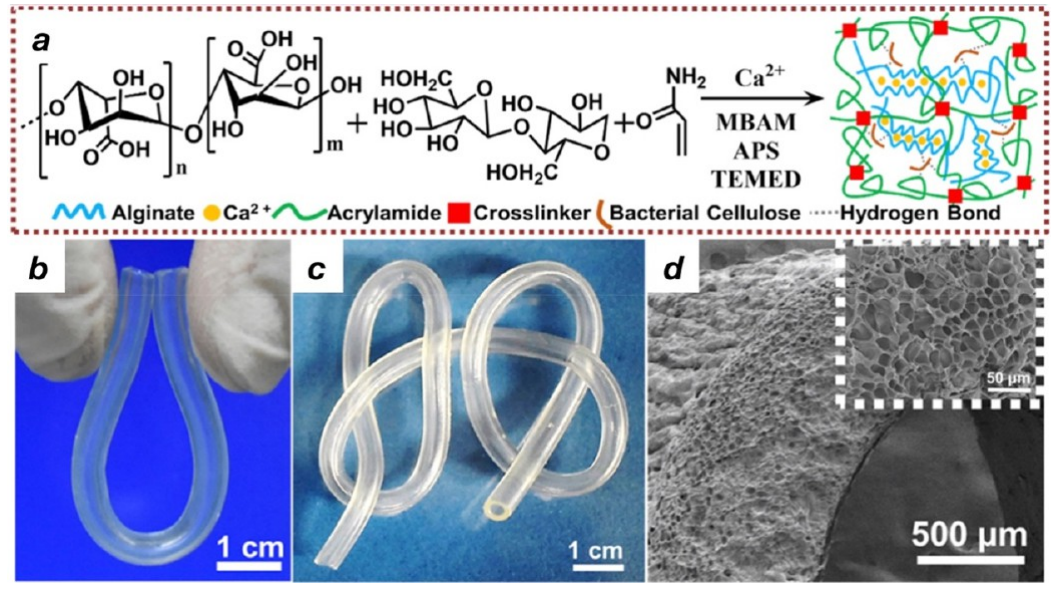

Figure 3. Tubular grafts printed using interfacial diffusion printing of Ca-Alg/PAAm dual-network hydrogels modified with bacterial cellulose. Adapted and reproduced with permission from ref 76. Copyright 2019 American Chemical Society.

example, a second static cross-linking can be used to reinforce the structure after printing, ${ }^{70}$ or static cross-linking can be used to regulate the viscosity by (partial) cross-linking before printing. $^{71}$

Other than the nature of the networks and the cross-linking chemistry there are several other methods to obtain the needed viscosity, gelation rates, and shear thinning properties. For one, the viscosity can be altered by adding cosolvents, composite materials, or various viscosity modifiers (e.g., alginate, cellulose). Materials with temperature-dependent viscosity have also proven useful. And last, processing conditions like dual syringe systems and a coaxial extrusion systems have been successfully employed as tools for viscosity control. Table 1 provides an overview of the various systems described in detail in the following sections.

2.1. Dynamic-Static Networks. 2.1.1. Ionic/Static CrossLinking. Within the category of dynamic/static cross-linking, one of the most widely used strategies is to combine covalent cross-linking with ionic cross-linking. Alginate is very frequently used for biomaterials, and a well-known example of a double-network hydrogel is the alginate/poly(acrylamide) (PAAm) system. Alginate is a naturally occurring polymer that can be cross-linked with multivalent cations that interact with its carboxylate groups. ${ }^{72}$ The poly(acrylamide) chains are covalently cross-linked with $N^{\prime}, N^{\prime}$-methylene bis(acrylamide) (MBAA). Because of the prevalence of alginate/PAAm, many attempts have been made to use this double-network hydrogel in $3 \mathrm{D}$ printing. We will briefly focus on this system as an archetypal example of the various approaches toward using DN in bioprinting applications.

Alginate/PAAm double-network hydrogels were first reported in 2012 by Sun et al., ${ }^{73}$ employing a one-pot synthesis method to prepare tough hydrogels. The energy dissipation provided by the ionically cross-linked alginate network generated enhanced toughness. Single-network alginate hydrogels are notoriously brittle, breaking at very low extension and with an elastic modulus of $17 \mathrm{kPa}$. On the contrary, single-network PAAm hydrogels are relatively elastic, extending more than 10 times their original length but breaking at low stress (usually under $50 \mathrm{kPa}$ with an elastic modulus of $8 \mathrm{kPa}$ ). In stark contrast, $\mathrm{Ca}-\mathrm{Alg} / \mathrm{PAAm}$ doublenetwork hydrogels have far superior mechanical properties depending on the network ratio and cross-link density, with a tensile strength of $500 \mathrm{kPa}$, elastic modulus of $50 \mathrm{kPa}$, and extension of more than 10 times their original length. Of note, acrylamide monomer is prohibitively toxic to cells, whereas the acrylamide polymer is considered benign. Consequently, the $\mathrm{Alg} / \mathrm{PAAm}$ system is better suited to use as a biomaterial ink rather than a bioink.

Bakarich et al. first reported 3D printing of a Alg/PAAm DN hydrogel in $2013^{74}$ with the aim of determining whether this type of hydrogel could be used in extrusion printing while 

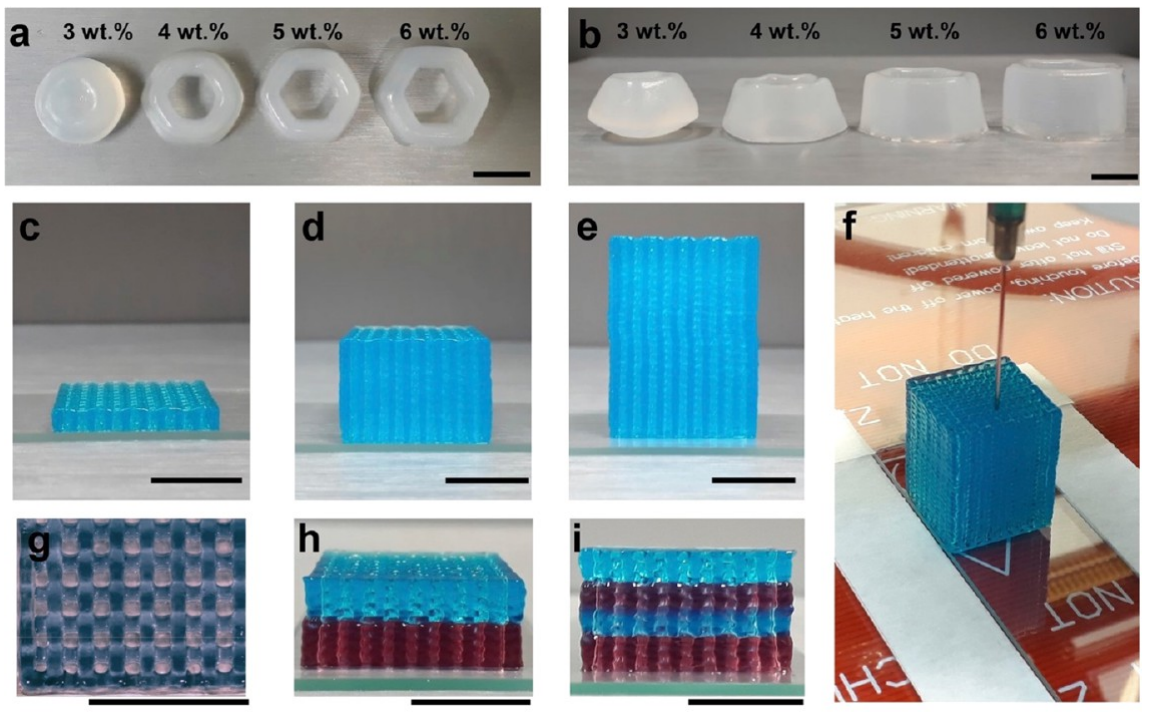

Figure 4. Incorporation of laponite into double-network alginate/PAAm hydrogels increases the printability of the double network. (a, b) Concentration of laponite has a marked effect on the printability, and optimization allows for the printing of (c) 10, (d) 50, and (e) 100 layer scaffolds via the (f) extrusion-based printing process with (g) good print fidelity. Furthermore, using a dual extruder, (h, i) multilayer scaffolds can be fabricated. Scale bars represent $10 \mathrm{~mm}$. Adapted and reproduced with permission from ref 64. Copyright 2018 Springer.

retaining the remarkable mechanical properties. Viscosity measurements was used to optimize the pregel solution before printing, and the addition of ethylene glycol as a cosolvent enabled suitable viscosity and shear-thinning behavior. Dogbone tensile bars were made using extrusion printing and cured with UV light after each deposited layer (Figure 2). In general, the hydrogels had smaller work of extension than the casted hydrogels reported by Sun et al. ${ }^{73}$ The structural flaws introduced by the filament-based printing process had a significant effect on the strain at failure as compared to the pristine cast hydrogels; however, the $3 \mathrm{D}$ printed hydrogel was still able to reach $300 \%$ elongation before break (900\% with the casted hydrogels). The mechanical properties of these printed hydrogels were superior to other printed alginate structures. The same authors also reported printing of a thermoresponsive alginate/poly $(N$-isopropylacrylamide) $\mathrm{DN}$ hydrogel using a similar procedure. ${ }^{75}$

In one of the most thorough examples for applying the alginate/PAAm system in $3 \mathrm{D}$ printing, Zhou et al. ${ }^{76}$ printed tubes using interfacial diffusion printing (Figure 3). A bioink consisting of water, alginate, acrylamide, bacterial cellulose, MBAA, and ammonium persulfate (APS, initiator) is extruded into a reactive aqueous medium consisting of calcium chloride and tetramethylethylenediamine (TEMED, catalyst). Upon diffusion of calcium chloride and TEMED the gelation is initiated and a hydrogel is formed. Bacterial cellulose provides extra cross-linking via hydrogen bonds and is added as a mechanical enhancement. Artificial tubular grafts with different diameters were printed and tested for their similarity to blood vessels. Rheological, tensile, and compression tests showed a Young's modulus $(0.5 \mathrm{kPa})$ similar to that of blood vessels $(0.2-0.6 \mathrm{MPa})$ and the hydrogels could return to their original shape after compression. Further analysis showed very good hemo- and cell compatibility.

There remain several other examples of alginate/PAAm printing with various modifications, however, without biocompatibility testing. Several of these strategies may have promising applications in biomedical engineering, yet must be more thoroughly tested for the suitability of tissue to grow within the scaffolds. For example, in 2017, Liu et al. reported an alginate/PAAm double-network hydrogel with enhanced mechanical properties via the inclusion of amino-graphene oxide (aGO). ${ }^{77}$ The alginate-aGO acts as a co-cross-linker in conjunction with $\mathrm{Ca}^{2+}$ and both increases the energy dissipation and introduces shear-thinning behavior essential for $3 \mathrm{D}$ printing. These cast materials showed impressive strength and elongation, $860 \mathrm{kPa}$ an $3300 \%$, respectively, which was significantly higher than the reference Ca-Alginate/ PAAm DN hydrogel. The authors directly compared cast hydrogels to $3 \mathrm{D}$ printed hydrogels and noticed a moderate decrease in strength and elongation in the $3 \mathrm{D}$ printed structures (300 $\mathrm{kPa}$ and $2400 \%$ ); these values nevertheless outperform the original control Ca-alginate/PAAm system. Although this study did not investigate the biocompatibility of these gels or their suitability for bioprinting, all components have established biocompatibility in other systems. ${ }^{78,79}$

Nanocomposite materials such as hydroxy apatite and laponite can also be used to improve printability by enhancing the shear-thinning properties of the bioink. The alginate/ PAAm double-network hydrogel has been used in combination with hydroxy apatite for the immobilization of glucose oxidase and catalase enzymes. ${ }^{80}$ Cast cylindrical shapes reached a compression modulus of up to $7 \mathrm{MPa}$, and multilayer printed mesh structures with immobilized enzymes showed 100\% protein recovery and $95 \%$ enzyme activity after 30 days. Laponite has also been shown to improve the printability of alginate/PAAm hydrogels, with structures of up to 100 layers being printed. The rheological properties of the laponite/ alginate/PAAm system have been studied extensively, but no biocompatibility tests have been performed. ${ }^{64}$ Nevertheless, intricately structured 3D scaffolds have been printed with fairly high resolution and impressive mechanics (Figure 4). The structural integrity was shown to depend highly on the concentration of laponite in the system. Ultimately, scaffolds with more than 40 layers were produced routinely with a dual extrusion printer head.

Another approach to $3 \mathrm{D}$ printing is using a dual syringe $3 \mathrm{D}$ printing system. Bootsma et al. ${ }^{81}$ printed cubic structures from 

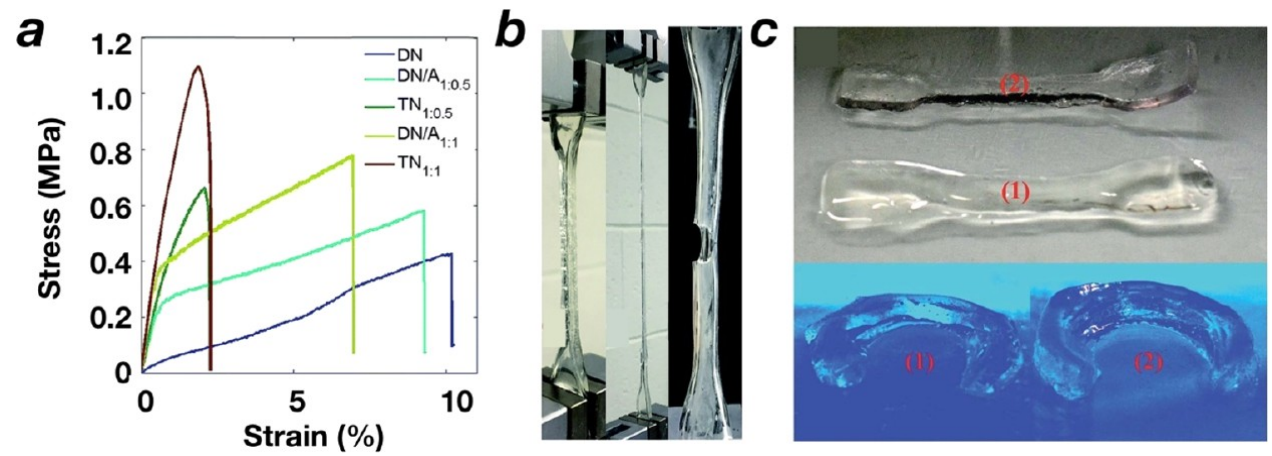

Figure 5. (a) Stress-strain curves and (b) photographs of tensile tests on dual and triple network structures comprising alginate, agar, and acrylamide components and (c) 3D printed structures including "dogbone" tensile bars and rings. Adapted and reproduced with permission from ref 83. Copyright 2015 Royal Society of Chemistry.

alginate/poly(acrylamide), alginate/poly(NiPAAm), and alginate/poly ${ }^{62}$ double-network hydrogels by using the $\mathrm{CaCO}_{3} /$ GDL system (introduced by Kuo and Ma in 2001) ${ }^{82}$ to control the gelation of alginate via slow release of $\mathrm{Ca}^{2+}$. One solution containing alginate, acrylamide, MBAA, and GDL was loaded into the first syringe. The second solution containing alginate, Irgacure, and $\mathrm{CaCO}_{3}$ was loaded into a separate syringe. Mixing of the two solutions occurs in a mixing head before extrusion. Upon extrusion, the acrylamide network is polymerized and cross-linked upon UV radiation. The structures are therefore printed and cross-linked simultaneously. Mechanical tests were performed on cylindrical samples cut out of a printed sheet and compressive moduli of up to $25 \mathrm{kPa}$ were reported.

Thermally induced sol-gel transitions can also be used to control the viscosity during printing. For example, an alginate/ poly(acrylamide) system by Wei et al. in 2015 used agar to leverage the thermal gelation upon printing. ${ }^{83}$ Optimal printing conditions of this thermally reversible Alg/PAAm/agar hydrogel were determined using rheology. Dog-bone samples were printed for tensile testing and reached a tensile strength and elastic modulus of up to $1 \mathrm{MPa}$ and $870 \mathrm{kPa}$, respectively, depending on the concentration and cross-linking of the alginate network (Figure 5). The mechanical properties of this "triple network" hydrogel were far superior to printed structures of double-network hydrogels such as alginate/ PAAm or Agar/PAAm. However, the use of sol-gel transition in this specific example is limited in bioprinting, as temperatures above $50{ }^{\circ} \mathrm{C}$ can induce cell death. Thermoresponsive polymers with transitions closer to physiological temperature could show promise with this strategy.

Although sometimes lacking the necessary compatibility studies for bioprinting, these examples of the archetypal alginate/PAAm system are pertinent illustrations of the different approaches to printing double-network hydrogels. An overview of printed double-network hydrogels that show use in tissue engineering or show promising advances follows below.

One promising system for tissue engineering is alginate/ hyaluronic acid catechol. ${ }^{84}$ Although alginate provides energy dissipation through dissociation of ionic bonds, covalent crosslinking (by oxidation with $\mathrm{NaIO}_{4}$ ) of the catechol groups on hyaluronic acid instills mechanical integrity on the hydrogel. Mechanical testing was performed on the cast double-network hydrogels, showing a compressive stress of $3.5 \mathrm{MPa}$, which is a drastic improvement compared to the alginate single network $(0.35 \mathrm{MPa})$ and HA single network $(0.16 \mathrm{MPa})$ (Figure 6a).

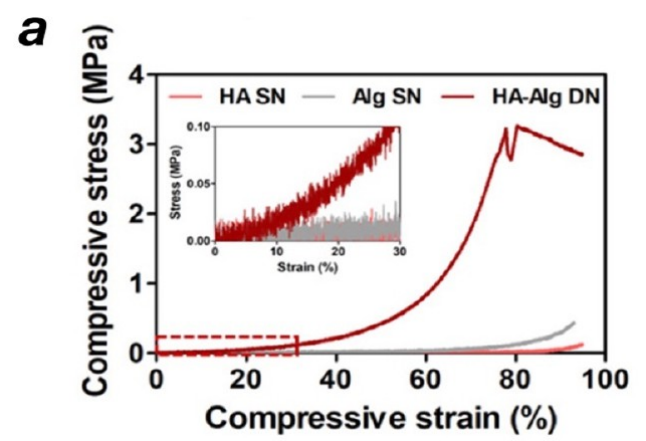

b

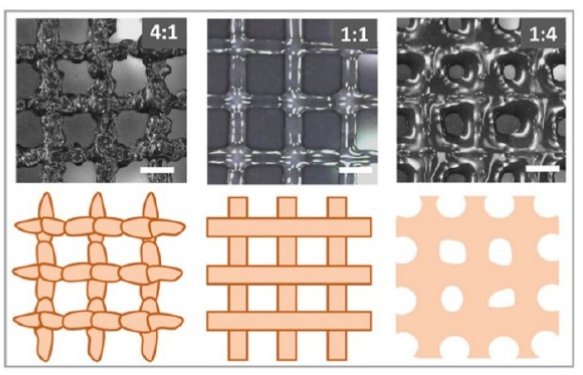

Figure 6. (a) Compression strength testing of single-network hyaluronic acid and alginate hydrogels and the comparison to the corresponding dual network; (b) several constructs 3D printed from the dual network. Adapted and reproduced with permission from ref 84. Copyright 2020 American Chemical Society.

Structures were printed using a two-step procedure. A solution containing partially cross-linked HA-catechol and alginate is first extruded. The $\mathrm{NaIO}_{4}$ and the alginate in the solution provide the viscosity and shear-thinning behavior essential for printing. The printed structure is than stabilized and strengthened in a second step by immersion in a $\mathrm{CaCl}_{2}$ solution to cross-link the alginate network (Figure 6b). Bioprinted cell-laden scaffolds were formed by encapsulating human umbilical vein endothelial cells (HUVECs) before extrusion. The printed structures showed cell viability of $95 \%$ after extrusion and $85 \%$ after 14 days.

In 2019, Trachsel et al. ${ }^{85}$ developed a printable cell-laden DN hydrogel matrix from enzymatically cross-linked poly(2alkyl-2-oxazoline) and ionically cross-linked alginate. Cellulose nanofibrils were added to improve shear thinning. Human auricular chondrocytes (HAuCs) were encapsulated within the matrix with high viability ( $90 \%$ after 21 days). Mechanical compression tests were performed with the DN hydrogel, 


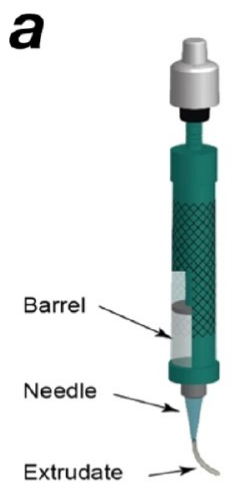

b

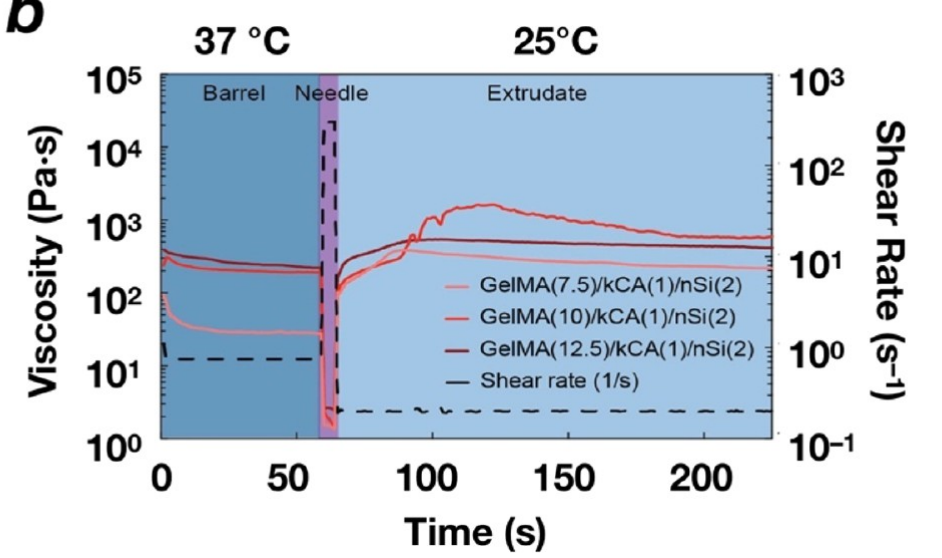

C

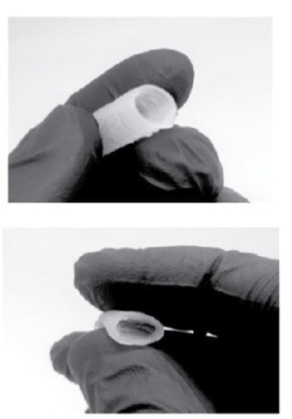

Figure 7. In a $\kappa$-carrageenean/gelMA dual network reinforced with laponite, (a) printability was correlated with rapid viscosity recovery and thermal gelation during the printing process. The strong double-network properties led to (b) bioprinted tube structures (7.5\% GelMA, $1 \% \kappa$-CG, $2 \%$ laponite) that could be completely collapsed and retain their shape. Adapted and reproduced with permission from ref 92 . Copyright 2020 American Chemical Society.

reaching a compressive modulus of only $30 \mathrm{kPa}$ for the cast samples. Hong et al. ${ }^{86}$ printed alginate/poly(ethylene glycol)diacrylate (PEGDA) hydrogels using laponite as a rheology modifier. A facile one-step procedure was used for printing, after which the structures were cross-linked under UV light. Multilayered structures such as a hollow cube, a pyramid, a nose, and an ear were printed. The biocompatibility of the printed hydrogel was investigated with human embryonic kidney cells encapsulated in a type 1 rat tail collagen solution that was gelled in the pores of the printed PEGDA/alginate/ nanoclay structure. This collagen/PEGDA/alginate/nanoclay bioprinted hydrogel showed high cell viability over 7 days (95\%).

Similar to the dual syringe system (vide supra), coaxial needles can also be used. For example, a bioink mixture containing alginate can flow out through the inner needle, whereas the ionic $\mathrm{CaCl}_{2}$ cross-linking solution flows through the outer needle. This allows inks with lower viscosity to be printed, as cross-linking happens immediately upon extrusion. A bioink composed of alginate and gelatin methacroyl was printed into a multilayered mesh grid structure using a coaxial needle extrusion system, employing UV light to cure the gelMA network after printing. ${ }^{87}$ The cell viability of human umbilical vein endothelial cells reached $75 \%$, even after $30 \mathrm{~s}$ of UV exposure. The same system has also been printed using a microgel-assisted extrusion process. ${ }^{88}$

Similar to alginate, $\kappa$-carrageenan can be ionically crosslinked. At temperatures below $75{ }^{\circ} \mathrm{C}, \kappa$-carrageenan has a helical structure. Introduction of cations $\left(\mathrm{K}^{+}, \mathrm{Ca}^{2+}, \mathrm{Na}^{2+}\right)$ at this temperature leads to aggregation of the helices. These intermolecular forces led to the formation of a threedimensional network. ${ }^{89}$ The sol-gel transition of $\kappa$-carrageenan can facilitate $3 \mathrm{D}$ printing, as demonstrated by Bakarich et al. ${ }^{90}$ A double-network hydrogel composed of $\kappa$-carrageenan and poly(oxyalkene amine) was used to print dumbbell shaped samples for mechanical evaluation. The structure integrity was further reinforced by covalently cross-linking the poly(oxyalkene amine) with poly(ethylene glycol)diglycidylether (PEGDGE) via an epoxy-amine addition mechanism after printing. The printed KCG/EA gels were shown to be significantly stronger than printed alginate/PAAm hydrogels, with strength and elastic modulus up to 600 and $320 \mathrm{kPa}$, respectively, and an extension of three times the original size. In 2017, Liu et al. employed a $\kappa$-carrageenan/poly(acrylamide) hydrogel in bioprinting. ${ }^{91}$ The precursor solution was heated $\left(40-70{ }^{\circ} \mathrm{C}\right)$ in the syringe prior to printing. After printing, the structures were UV-cured for $1 \mathrm{~h}$ to polymerize AAm/MBAA. Different 3D structures (e.g., mesh pattern, hollow prism, and hollow cube) were printed. However, as this publication focused on the application as a strain sensor, no biocompatibility studies were performed. Printing of a $\kappa$-carrageenan/ gelMA hydrogels was reported in $2020 .^{92}$ This work uses a combination of nanoreinforcements of laponite and the thermal gelation of gelMA after extrusion (Figure 7). Before extrusion, the pregel solution is heated to $37^{\circ} \mathrm{C}$. The ink was covalently cross-linked with UV light and ionically cross-linked through submersion in a $5 \% \mathrm{KCl}$ solution after extrusion. Compression tests were performed on a similar GelMA/ $\kappa$-CG/ laponite hydrogel and compared to the single-network hydrogels in a previous publication. ${ }^{93}$ Furthermore, cell viability tests were performed with human mesenchymal stem cells.

2.1.2. Dynamic Covalent/Static Cross-Linking. All of the above examples combine ionic cross-linking with covalent cross-linking. There are a few other examples of dynamic crosslinking that can be used to obtain a static/dynamic system. One of those is using dynamic covalent cross-linking such as hydrazone, imines, borate esters, and oxime bonds. In 2018 a hyaluronic acid double-network hydrogel was reported using hydrazone dynamic cross-linking. ${ }^{94}$ Hyaluronic acid (HA) is a glycosaminoglycan that is a constituent of the extracellular matrix in human tissue. HA has been used in several clinical applications owing to its biocompatibility. However, HA alone is not suitable for printing; chemical modification is often required to improve its properties. Modifying HA with hydrazide (HA-HYD) and aldehyde (HA-ALD) groups enables a dynamic covalent hydrazone cross-linking character. Dynamic covalent bonding provides the system with an energy dissipation mechanism as well as shear-thinning properties essential for printing. Mechanical integrity can be maintained by combining covalent cross-linking in the system, for example, through covalent cross-linking of hyaluronic acid norborene with multivalent thiols via thiol-ene chemistry. The thiol-ene click reaction can be photoinitiated in (e.g., UV radiation) after 
printing. The dual-network hydrogels showed a similar strain at failure $(\sim 75 \%)$ but an increased failure stress $(25 \mathrm{vs} 11 \mathrm{kPa})$ as compared to the non-cross-linked (only supramolecular network) samples.

2.1.3. Supramolecular Interactions/Static Cross-Linking. In a similar fashion, supramolecular interactions can be used as dynamic cross-linking. For example, functionalizing HA with adamantane (HA-ADA) and cyclodextrin (HA-CD) supramolecular host-guest interactions led to shear-thinning properties. Combining this with methacrylation of the HA gave rise to a double-network hydrogel after curing, ${ }^{70}$ with enhanced fiber resolution compared with the individual networks. However, evaluating toughness in this system is still needed to uncover the potential mechanical benefits of the double network.

2.1.4. Hydrogen Bonding/Static Cross-Linking. A last example of static/dynamic DN hydrogels uses a combination of covalent cross-linking and hydrogen bonding. In 2019, Gao et al. $^{95}$ reported a double-network hydrogel composed of covalently cross-linked gelatin methacrylate (gelMA) and poly( $N$-acryloyl 2-glycine) (PACG). The two carboxyl groups present on the PACG backbone form hydrogen bonds, acting as an energy dissipation sink and thereby strengthening the hydrogel. The viscosity of the bioink was altered using the thermoreversible sol-gel transition $\left(20-40{ }^{\circ} \mathrm{C}\right)$ and was found suitable for $3 \mathrm{D}$ printing because of its recovery after shear strain. Mechanical testing of the cast hydrogels showed compressive strength up to $12 \mathrm{MPa}$, tensile strengths up to 1 $\mathrm{MPa}$, extension up to $250 \%$, and a Young's modulus up to 250 $\mathrm{kPa}$, which are superior to the values for the single-network GelMA (no comparison was made with SN PACG). Degradation of the scaffold in collagenase solution ranged from 7 to 100 days, dependent on the composition, with lower degradation rates for higher ACG contents. Furthermore, gelMA/PACG $/ \mathrm{Mn}^{2+}$ gels promote cell adhesion and proliferation of hBMSCs. Osteochondral scaffolds (gradient scaffolds) were printed using an air-extrusion fabrication method. Printing cartridges were kept at $20{ }^{\circ} \mathrm{C}$ during fabrication on a platform at $-10{ }^{\circ} \mathrm{C}$, followed by UV irradiation (compressive strength up to $2.5 \mathrm{MPa}$ and compressive modulus of up to $250 \mathrm{kPa}$ ). Although these results are very promising, the system was not printed with cells.

2.2. Dynamic/Dynamic Networks. Dynamic/dynamic DN hydrogels make exclusive use of reversible cross-linking, such as ionic interactions, H-bonding, dynamic covalent bonds, and supramolecular interactions. Obtaining strong hydrogels using exclusively dynamic interactions remains formidable. As such, only a few examples of printed DN hydrogels are reported in this category. A DN hydrogel consisting of alginate and poly(acrylamide-co-acrylic acid) was printed by $\mathrm{Li}$ et al., using only ionic cross-linking with $\mathrm{Fe}^{3+} .{ }^{96}$ The viscosity of the ink was adjusted using silicone oil (ca. 10 wt \%). Cast hydrogels showed remarkable mechanical properties with tensile stress up to $2.5 \mathrm{MPa}$ and strain up to $1500 \%$. Although cast samples displayed impressive mechanics, these hydrogels could only be printed in very acidic $(\mathrm{pH} 1)$ or very alkaline ( $\mathrm{pH}$ 14) conditions.

For PVA, a freeze/thaw method was used to produce hydrogels in which PVA crystallites serve as physical crosslinks. In combination with an ionically cross-linked hyaluronic acid network, tough hydrogels (toughness of $19.6 \mathrm{MJ} / \mathrm{m}^{3}, E=$ $10 \mathrm{MPa}$ ) were formed without any polymerization reactions being applied. ${ }^{97}$ The necessary viscoelastic properties for printing were achieved by using high molar mass HA. The precursor solution was printed into different patterns, after which they were dehydrated, annealed at high temperature, and immersed in an $\mathrm{FeCl}_{3}$ solution. Although the cast PVA/ HA acid hydrogels show promising mechanical properties, additional testing was not performed on the printed structures. Furthermore, no swelling experiments or cell viability tests were performed.

2.3. Static/Static Networks. In 2017, a multistep 3D printing procedure for printing PAMPS/PAAm DN hydrogels was reported. ${ }^{98}$ Laponite nanoclay was used to alter the viscosity and shear-thinning properties of the ink. An extrusion printer was used to print a pregel solution containing Laponite, AMPS, MBAA, and photoinitiator. The structures were cured with UV light after printing to obtain the covalently crosslinked PAMPS network. This gel was subsequently soaked in a mixture containing acrylamide, MBAA, and photoinitiator. The second network was thus formed after further UV curing. Dogbone samples were printed for mechanical testing and evaluated for their potential as a meniscus replacement, with the best match having a stiffness of $0.44 \mathrm{MPa}$.

\section{DN AS INJECTABLE HYDROGELS}

In the field of tissue engineering, hydrogels that can be formed in situ by injection into the human body have many advantages; injectable hydrogels offer minimally invasive and less painful treatments, the ability to fill complex voids or form unusual shapes, and the ability to carry and transport functional biomolecules and/or cells. As previously mentioned for bioinks, the focus of injectable hydrogel design has been shifted from covalent and static networks to stimuli-responsive and dynamic hydrogels that perform better as biomimetic materials. The mechanical properties have a key role in the therapeutic potential of hydrogels for tissue regeneration, and most conventional, single-network hydrogels lack the mechanical strength exhibited by many natural tissues (e.g., bones, cartilage, muscle, and ligaments). Because static covalently cross-linked hydrogels are typically brittle and dynamic hydrogels often exhibit pseudoplastic deformation with low resistance to loading, double-network hydrogels have become an attractive strategy to recapitulate stiffness and biological tissue's resilience toward repeated loading. ${ }^{107}$

The preparation of double networks as injectable hydrogels is still challenging. An injectable hydrogel initially requires fluidity followed by fast gelation after injection in order to establish mechanical integrity at the injection site. An ideal injectable hydrogel exhibits shear-thinning behavior that facilitates flow through a needle and allows shape filling within complicated tissue scaffolds. ${ }^{108-110}$ The material should readily interact with or adhere to neighboring tissues. It must solidify by chemical or physical cross-linking in situ and promote regeneration of new tissue. Naturally, the injectable material must be biocompatible, stable at physiological conditions, biodegradable, and mechanically robust. Thus, double networks can be designed to embody many of these characteristics, and are a promising strategy not only to improve mechanical properties but also to enhance the biological properties by including natural polymers, which generally are biocompatible and favor cell adhesion and proliferation. Interestingly, although significant focus has been on shear thinning (i.e., rheological) behavior and its relation to injectability, recent modeling from Appel and co-workers 
Table 2. Summary of Dual-Network Hydrogels Used for Injection

\begin{tabular}{|c|c|c|c|c|}
\hline $\begin{array}{l}\text { polymer } \\
\text { source }\end{array}$ & polymer networks & cell-laden & key details & ref \\
\hline \multicolumn{5}{|c|}{ Dynamic/Static Networks } \\
\hline \multirow{2}{*}{$\begin{array}{l}\text { natural/ } \\
\text { synthetic }\end{array}$} & $\mathrm{C}-\mathrm{C}$ (photocuring, covalent)/ ionic (physic) & CCD-112CoN human & tissue engineering $(\mathrm{TE})$ & 112 \\
\hline & 1-PEGMA and MBAA. & fibroblasts & $\begin{array}{l}\text { one single solution with all components except } \mathrm{CaCl}_{2} \text {, injection } \\
\text { was not tested }\end{array}$ & \\
\hline \multirow[t]{3}{*}{$\begin{array}{l}\text { natural/ } \\
\text { natural }\end{array}$} & $\begin{array}{l}\text { 2-alginate and } \mathrm{Ca}^{2+} \\
\text { amide (covalent)/ionic (physic)/H bond } \\
\quad \text { (supramolecular) }\end{array}$ & NIH $3 \mathrm{~T} 3$ fibroblasts & $\begin{array}{l}\text { rheological properties of DN slightly higher than that of SN } \\
\text { bone TE }\end{array}$ & 113 \\
\hline & 1-alginate and gelatin, EDC/NHS & & two-step method for preparation, injection was not tested & \\
\hline & 2-alginate and $\mathrm{Zn}^{2+}$ & & $\begin{array}{l}\text { mechanical properties of DN were two times higher than that of } \\
\text { SN }\end{array}$ & \\
\hline \multirow{3}{*}{$\begin{array}{l}\text { natural/ } \\
\text { natural }\end{array}$} & host-guest (supramolecular)/C-S (covalent) & MSCs & load-bearing materials for TE & 107 \\
\hline & 1-CD-HA and ADA-HA & & on- pot method & \\
\hline & 2-methacrylated HA and dithiothreitol & & $\begin{array}{l}\text { addition of methacrylic groups on HA improved the mechanical } \\
\text { properties of DN }\end{array}$ & \\
\hline \multirow{3}{*}{$\begin{array}{l}\text { natural/ } \\
\text { synthetic }\end{array}$} & thermal, folding (physical)/amide (covalent) & NIH $3 \mathrm{~T} 3$ fibroblasts & cell research and $\mathrm{TE}$ & 114 \\
\hline & 1-agarose & & one-pot method & \\
\hline & 2-4-arm-PEG-NH2 and 4-arm-PEG-NHS & & $\begin{array}{l}\text { DN enhanced the mechanical properties and the energy } \\
\text { dissipation capacity compared to SN }\end{array}$ & \\
\hline \multirow{3}{*}{$\begin{array}{l}\text { natural/ } \\
\text { natural }\end{array}$} & $\mathrm{C}-\mathrm{C}$ (photocuring, covalent)/imine ( $\mathrm{DCvC})$ & L929 fibroblasts & regenerative medicine and $\mathrm{TE}$ & 115 \\
\hline & $\begin{array}{l}\text { 1-oxidized alginate with acrylate groups } \\
\text { (AMSA), UV }\end{array}$ & & dual syringe method & \\
\hline & 2-aminogelatin and AMSA & & $\mathrm{DN}$ enhanced the mechanical properties compared to SN & \\
\hline \multirow{3}{*}{$\begin{array}{l}\text { natural/ } \\
\text { natural }\end{array}$} & $\mathrm{C}-\mathrm{C}$ (photocuring, covalent)/imine ( $\mathrm{DCvC})$ & L929 fibroblasts & articular cartilage repair & 116 \\
\hline & 1-oxidized dextran and gelatin & & one-step method, but injection was not tested & \\
\hline & 2-gelMA, UV & & DN showed superior mechanical properties compared to SN & \\
\hline \multirow{4}{*}{$\begin{array}{l}\text { natural/ } \\
\text { synthetic }\end{array}$} & & Dynamic/Dynamic Net & works & \\
\hline & borate ester $(\mathrm{DCvC}) /$ imine $(\mathrm{DCvC})$ & SMMC-7721 human & drug delivery and TE & 117 \\
\hline & $\begin{array}{l}\text { 1-PVA and PEG functionalized with } \\
\text { phenylboronic acid (MF-PEG), }\end{array}$ & hepatoma cells & one-pot method & \\
\hline & 2-glycol chitosan and MF PEG & & $\begin{array}{l}\text { DN enhanced strength and mucoadhesive properties compared } \\
\text { to SN }\end{array}$ & \\
\hline \multirow{3}{*}{$\begin{array}{l}\text { natural/ } \\
\text { natural }\end{array}$} & imine $(\mathrm{DCvC}) /$ imine $(\mathrm{DCvC})$ & $\mathrm{C} 2 \mathrm{C} 12$ myoblasts and & drug delivery and TE & 118 \\
\hline & 1-carboxymethyl chitosan and oxidized dextran & adipose-derived & one-step method, but injection was not tested & \\
\hline & $\begin{array}{l}\text { 2-polyaniline-grafted gelatin and oxidized } \\
\text { dextran }\end{array}$ & & SN mechanical properties were not tested & \\
\hline \multirow{3}{*}{$\begin{array}{l}\text { natural/ } \\
\text { natural }\end{array}$} & imine $(\mathrm{DCvC}) /$ hydrazone $(\mathrm{DCvC})$ & NIH $3 \mathrm{~T} 3$ fibroblasts & TE and drug delivery & 119 \\
\hline & 1-oxidized alginate and gelatin & & one-pot method & \\
\hline & 2-oxidized alginate and adipic acid dihydrazide & & $\begin{array}{l}\text { only the mechanical and rheological properties of DN were } \\
\text { tested }\end{array}$ & \\
\hline \multirow[t]{3}{*}{$\begin{array}{l}\text { natural/ } \\
\text { natural }\end{array}$} & $\begin{array}{l}\text { thermal, folding (physical)/thermal, folding } \\
\text { (physical) }\end{array}$ & in vivo & drug delivery & 120 \\
\hline & 1-methylcellulose & & one-pot method & \\
\hline & 2-xanthan gum & & rheological properties are slightly better than those of SN & \\
\hline \multirow[t]{3}{*}{$\begin{array}{l}\text { natural/ } \\
\text { synthetic }\end{array}$} & $\begin{array}{l}\text { thermal, folding (physical)/Hbond } \\
\text { (supramolecular) }\end{array}$ & $\begin{array}{l}\text { human adipose-derived } \\
\text { MSCs }\end{array}$ & cell delivery & 121 \\
\hline & 1-8-arm-PEG- P1(protein)-PNIPAM copolymer & & one-pot method & \\
\hline & 2-C7 (protein) & & $\begin{array}{l}\text { mechanical properties of supramolecular network improved by } \\
\text { adding NIPA as block unit to } 8 \text {-arm-PEG-P1 }\end{array}$ & \\
\hline \multirow{3}{*}{$\begin{array}{l}\text { natural/ } \\
\text { synthetic }\end{array}$} & ionic (physic)/H bond (physic) & L929 fibroblasts in vivo & bone TE & 122 \\
\hline & $\begin{array}{l}\text { 1-4-carboxyphenylboronic acid grafted PVA and } \\
\mathrm{Ca}^{2+}\end{array}$ & & one-pot method & \\
\hline & 2-bioactive glass (BG) and PEG & & $\begin{array}{l}\text { both } \mathrm{DN} \text { and } \mathrm{BG} \text { improved the mechanical properties (tough } \\
\text { hydrogels) compared to SN }\end{array}$ & \\
\hline \multirow[t]{3}{*}{$\begin{array}{l}\text { natural/ } \\
\text { natural }\end{array}$} & $\begin{array}{l}\text { hybridization (physic)/host-guest } \\
\text { (supramolecular) }\end{array}$ & & dynamic surface coatings, controlled release, and TE & 123 \\
\hline & 1-DNA Y and DNA linker & & one-pot method & \\
\hline & $\begin{array}{l}\text { 2-phenylalanine-grafted carboxymethyl cellulose } \\
\text { and cucurbit[8] uril }\end{array}$ & & compression modulus of $\mathrm{DN}$ is slightly higher than that of $\mathrm{SN}$ & \\
\hline \multirow{3}{*}{$\begin{array}{l}\text { natural/ } \\
\text { natural }\end{array}$} & imine $(\mathrm{DCvC}) /$ ionic (physic) & & cell delivery for cartilage repair & 124 \\
\hline & 1-glycol chitosan and dialdehyde-PEO & & dual syringe method & \\
\hline & 2-alginate and $\mathrm{Ca}^{2+}$ & & $\begin{array}{l}\text { mechanical properties of DN increased remarkably compared to } \\
\text { SN }\end{array}$ & \\
\hline \multirow{2}{*}{$\begin{array}{c}\text { natural/ } \\
\text { natural }\end{array}$} & imine $(\mathrm{DCvC}) /$ ionic (physic) & \multirow{2}{*}{$\begin{array}{l}\text { VECs and BN- MSCs, } \\
\text { in vivo }\end{array}$} & bone TE & 125 \\
\hline & 1-lycol chitosan and dialdehyde-PEO & & dual syringe method & \\
\hline
\end{tabular}




\section{Table 2. continued}

\begin{tabular}{|c|c|c|c|c|}
\hline $\begin{array}{l}\text { polymer } \\
\text { source }\end{array}$ & polymer networks & cell-laden & key details & ref \\
\hline \multicolumn{5}{|c|}{ Dynamic/Dynamic Networks } \\
\hline \multirow{4}{*}{$\begin{array}{l}\text { natural/ } \\
\text { natural }\end{array}$} & 2-alginate and $\mathrm{Ca}^{2+}$ & & $\begin{array}{l}\text { mechanical properties of } \mathrm{DN} \text { increased remarkably compared to } \\
\text { SN }\end{array}$ & \\
\hline & $\begin{array}{l}\text { thermal, folding (physical)/DA chemistry } \\
\text { (DCvC) }\end{array}$ & & cell therapy and TE & 19 \\
\hline & 1-Pluronic F127-grafted chitosan & & one-pot method & \\
\hline & 2-furan-gelatin and maleimide-PEG & & rheological properties of $\mathrm{DN}$ improved compared to $\mathrm{SN}$ & \\
\hline \multirow{3}{*}{$\begin{array}{l}\text { natural/ } \\
\text { natural }\end{array}$} & hydrazone (DCvC)/thermal, folding (physical) & human adult MSCs & injectable delivery of stem cells & 126 \\
\hline & $\begin{array}{l}\text { 1-hydrazine-modified elastin-like protein (ELP- } \\
\text { HYD) and aldehyde-modified hyaluronic acid. }\end{array}$ & & one-pot method & \\
\hline & 2-ELP & & $\begin{array}{l}\text { DN showed a remarkable enhancement of rheological properties } \\
\text { compared to SN }\end{array}$ & \\
\hline \multirow{3}{*}{$\begin{array}{l}\text { natural/ } \\
\text { natural }\end{array}$} & thermal, folding (physical)/imine ( $\mathrm{DCvC})$ & NIH $3 \mathrm{~T} 3$ fibroblasts & protein immobilization, cell/drug delivery, and TE & 127 \\
\hline & 1-agar & & one-pot method & \\
\hline & $\begin{array}{l}\text { 2-glycol-chitosan and oxidized carboxymethyl } \\
\text { cellulose }\end{array}$ & & $\begin{array}{l}\text { fracture energy of } \mathrm{DN} \text { was higher than that of } \mathrm{SN} \text {, but the } \\
\text { compression modulus of } \mathrm{DN} \text { did not improve compared to } \\
\text { SN }\end{array}$ & \\
\hline \multirow[t]{3}{*}{$\begin{array}{l}\text { natural/ } \\
\text { synthetic }\end{array}$} & $\begin{array}{l}\text { hydrophobic interactions (physic)/imine } \\
\text { (DCvC) }\end{array}$ & $\begin{array}{l}\text { antibacterial tests, L929 } \\
\text { fibroblasts in vivo }\end{array}$ & skin wound healing & 128 \\
\hline & $\begin{array}{l}\text { 1-benzaldehyde-terminated Pluronic F127 } \\
\text { (PF127-CHO) }\end{array}$ & & one-pot method & \\
\hline & 2-chitosan and PF127-CHO & & only the mechanical properties of $\mathrm{DN}$ were tested & \\
\hline \multirow{3}{*}{$\begin{array}{l}\text { synthetic/ } \\
\text { synthetic }\end{array}$} & $\mathrm{H}$ bond (physical)/hydrazone ( $\mathrm{DCvC})$ & L2929 fibroblasts & stressful working tissues & 129 \\
\hline & 1 PAA-co-PDAAM and adipic acid dihydrazide & & one-pot method & \\
\hline & 2-PAA-co-PDAAM and PVP & & DN strategy enables strong and tough hydrogels & \\
\hline \multirow{3}{*}{$\begin{array}{l}\text { synthetic/ } \\
\text { synthetic }\end{array}$} & $\mathrm{H}$ bond (physical)/hydrazone (DCvC) & - & TE and drug delivery & 130 \\
\hline & $\begin{array}{l}\text { 1-hydrazide-functionalized PNIPAM and } \\
\text { dialdehyde dextrin }\end{array}$ & & dual syringe method & \\
\hline & 2-poly(N-acryloyl glycinamide) PNAGA & & $\mathrm{DN}$ enhanced the mechanical properties compared to $\mathrm{SN}$ & \\
\hline \multirow{4}{*}{$\begin{array}{c}\text { natural/ } \\
\text { natural }\end{array}$} & \multicolumn{3}{|c|}{ Static/Static Networks } & \\
\hline & covalent/covalent & MG63 human & $\mathrm{TE}$ & 131 \\
\hline & 1-thiol-HA and 2-dithiopyridyl-HA & osteosarcoma cells & $\begin{array}{l}\text { first, two solutions were prepared and then mixed in one single } \\
\text { syringe }\end{array}$ & \\
\hline & 2-fibrinogen with thrombin & & DN showed an increased stiffness compared to fibrin SN & \\
\hline
\end{tabular}

suggests that shear rate, extrusion pressure, and syringe selection all play critical roles in determining injectability. ${ }^{111}$

3.1. Dynamic/Static Networks. The majority of examples of dynamic/static DN hydrogels for injectability were obtained by combining both physically and chemically cross-linked networks. Although photocuring (of olefins) is the most common approach to form covalent cross-links, there are many variations of noncovalent cross-linking, including electrostatic interactions, host-guest assembly, and thermally induced folding. Table 2 provides an overview of the systems covered in this section, whereby the examples are categorized by crosslink character (i.e., static/dynamic), with additional details regarding specific network composition included.

3.1.1. Dynamic Ionic/Static Covalent. Chee et al. reported one of the first examples of an injectable double-network system. ${ }^{112} \mathrm{DN}$ hydrogels were constructed of biocompatible poly(ethylene glycol) methyl ether methacrylate (PEGMA) and alginate. The authors described the initial UV curing to form a PEGMA network followed by alginate cross-linking with $\mathrm{CaCl}_{2}$. Selection of materials was based primarily on biocompatibility. In addition, the authors highlight that alginate solutions have purported shielding effects to protect cells from otherwise destructive mechanical force/shearing during injection. Even though the fibroblast viability and mechanical properties were not compared with the corresponding single networks, this work served as an important early framework demonstrating the potential of DN hydrogels as injectable scaffolds.

3.1.2. Dynamic Supramolecular (H Bond, GH, Thermal Folding)/Static Covalent. An alternative strategy to produce two independent networks involves using a dual syringe, as was proposed by $\mathrm{Bu}$ et al. and Rodell et al. in the following examples. ${ }^{107,114}$ According to the description, initial crosslinking occurs only when the two solutions are mixed in situ.

In the first example, four-armed poly(ethylene glycol) succinimidyl ester (4-arm-PEG-NHS) and four-armed poly(ethylene glycol) amine (4-arm-PEG- $\mathrm{NH}_{2}$ ) were reacted to form amides under physiological conditions. The second physically cross-linked network was based on thermally induced folding of agarose. ${ }^{114}$ Although details of the gelation time and rheological characterization were absent, the dual network led to enhanced mechanical properties (compression modulus of 8-30 MPa for a composition range of 4-10 wt \% PEG) compared to single networks $(<5 \mathrm{MPa})$. The authors suggested that the agarose network ruptures into small clusters and dissipates energy contributing to pronounced hysteresis during compression. Employing a double network not only improved stiffness but also enhanced energy dissipation and provided deformation-recovery ability due to the physical (i.e., noncovalent) nature of the second network. Promising injectability and biocompatibility (in vitro and in vivo) were also reported for these DN hydrogels. 
In the second example, supramolecular host-guest (HG) assembly was utilized to develop a rapidly self-healing primary network, where $\beta$-cyclodextrin (CD) and adamantane (Ad) were chosen as the host and guest, respectively, because of their high-affinity complexation. ${ }^{107}$ Hyaluronic acid (HA) was separately coupled with $\mathrm{CD}$ and Ad to form CD-HA and Ad$\mathrm{HA}$, respectively. The second network was obtained by Michael addition between methacrylate-HA (Me-HA) and dithiothreitol (DTT) at $\mathrm{pH}$ 8. Two precursor solutions were prepared, (1) CD-HA and Me-HA and (2) Ad-HA and DTT, which were mixed to prepare the final DN hydrogel. Gelation occurred immediately and the material exhibited impressive mechanical properties, which were tunable by the GH hydrogel concentration (compressive modulus between 2 and $50 \mathrm{kPa}$ ). However, the materials were ductile and deformation was nonrecoverable. In an effort to improve mechanical performance, the authors incorporated methacrylate groups to the HG network (MethGH DN), leading to compressive moduli between 2 and $220 \mathrm{kPa}$. MethGH DN hydrogels demonstrated exceptional recovery with only minor and localized defects observed. The supramolecular interactions gave rise to selfhealing properties due to rapid and reversible association, similar to many biological tissues. The dynamic supramolecular bonds enabled injection, which is crucial for minimally invasive delivery in biomedical applications. Furthermore, the DN hydrogels showed high cell viability with MSCs (ca. 95\%), with the ability for the cells to increase metabolic activity over 14 days post-encapsulation.

DN hydrogels comprising two non-independent cross-linked networks have also been reported. In general, these cases involve a polymer that has orthogonal functional groups capable of generating different types of bonds.

For example, Wang et al. proposed a DN hydrogel in which alginate is cross-linked with gelatin by amides (EDC/NHS coupling) and with itself by ionic interactions with zinc ions. ${ }^{113}$ The material included nanocrystalline cellulose (NCC) for nanoreinforcement to improve mechanical properties with the aim of applying these hydrogels in bone tissue regeneration. Compression moduli of hydrogels (without NCC) decrease with pore size (from 50 to $37 \mathrm{kPa}$ ), but the opposite behavior was observed for NCC hydrogels (from 75 to $92 \mathrm{kPa}$ ). The chemical and physical cross-linking allowed tuning the mechanical properties and stability of DN hydrogel. The chemical cross-linking using EDC/NHS created a stable amide linkage and improved hydrogel life, whereas the hydrogen bonding and hydrophobic interaction of NCC led to improved mechanics. Furthermore, NCC improved the degradation rate (from 50 to $85 \%$ at day 7) and swelling percentage (from 1400 to $900 \%$ at $24 \mathrm{~h}$ ). The potential for healing bone defects was suggested by the authors.

3.1.3. Dynamic Covalent/Static Covalent. Yuan et al. proposed a double network based on dual cross-linked alginate with both dynamic covalent and covalent cross-links. ${ }^{115}$ In this case, alginate was first oxidized to generate aldehyde groups and then reacted with 2-aminoethylmethacrylate through EDC/NHS coupling to form a multifunctional alginate (AMSA). Thus, amine groups of amino gelatin (AG, gelatin previously modified with ethylendiamine) and aldehyde groups of AMSA reacted quickly (120 s) via Schiff base condensation to form the primary network, and then acrylate groups of AMSA reacted $(15 \mathrm{~min})$ via UV irradiation to produce the secondary network. These gels were injected with a dual syringe method to form the final hybrid gel constructs, whereupon mechanical testing was performed (Figure 8a). Compared with the single-network analogs, the AMSA/AG
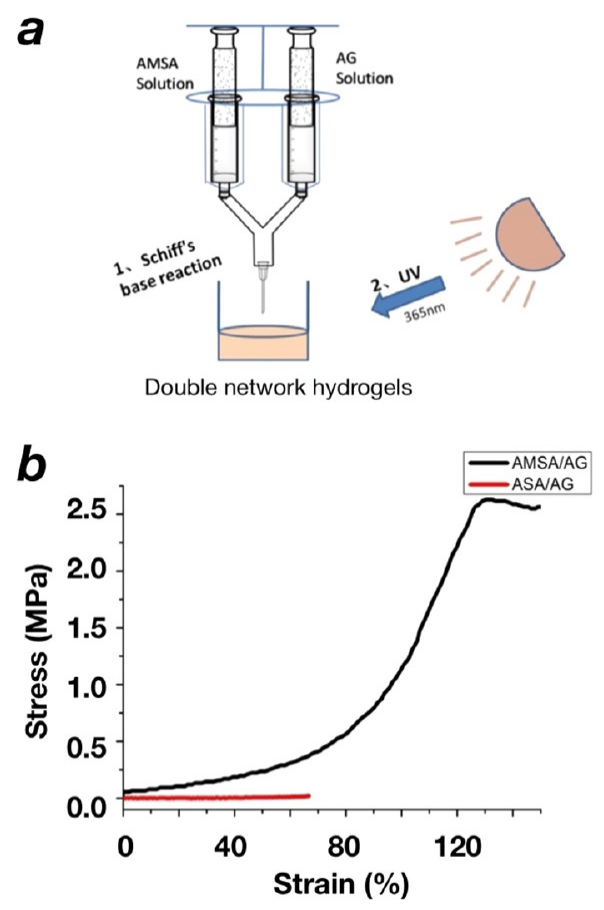

Figure 8. (a) Dual syringe injection method employed on alginategelatin dual-network systems and (b) tensile tests comparing the dual network with the corresponding single network. Adapted and reproduced with permission from ref 115. Copyright 2017 Elsevier.

dual cross-linked hydrogels showed higher cross-link density, enhanced mechanical properties (fracture stress 0.015 and 2.5 $\mathrm{MPa}$, respectively), lower swelling ratio (3 and 2, respectively), and lower degradation rate (40 and $70 \%$ mass remaining at day 30 , respectively) (Figure $8 \mathrm{~b}$ ). In addition, the in vitro cytotoxicity activity of L929 cells on the hydrogels surface tests showed that the double-network hydrogels allow proliferation of cells over 4 days when modified with RGD peptides.

Zhou et al. proposed a similar double-network strategy using a combination of static- and dynamic-covalent cross-linking. ${ }^{116}$ As in the previous example, the first network was cross-linked via Schiff-base reaction (between gelatin and oxidized dextran) and the second network was formed by UV irradiation (gelatin methacrylate GelMA). The authors suggested that the lower swelling ratios of DN hydrogels relative to SN hydrogels led to lower degradation rate. Combining dynamic covalent crosslinking (imine bonds) and photo-cross-linking ( $\mathrm{C}-\mathrm{C}$ bonds) also improved the mechanical properties $\left(G^{\prime}=7.3 \mathrm{kPa}\right.$, compression modulus $=270 \mathrm{kPa})$ compared to single network (GelMA $G^{\prime}=2.3 \mathrm{kPa}$, compressive modulus $\left.=77 \mathrm{kPa}\right)$. In addition, the reversible nature of imine linkages enabled rapid shape recovery after deformation. The aldehyde groups in the DN hydrogel were also suggested to react with amine groups of cartilage tissue via Schiff-base coupling to promote integration and improve adhesion to tissue. Thus, the dynamic covalent cross-linking improved both mechanical properties and tissue integration. Furthermore, the DN gels exhibited biocompatibility and enhanced formation of hyaline cartilagelike tissues. 
a

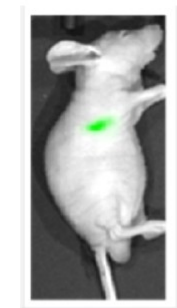

C
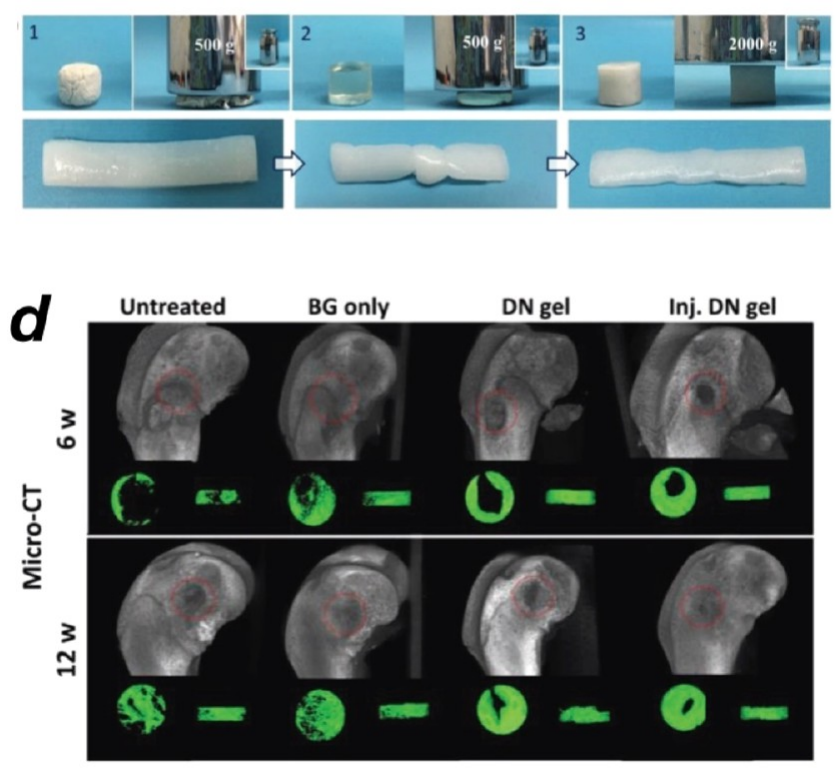

b

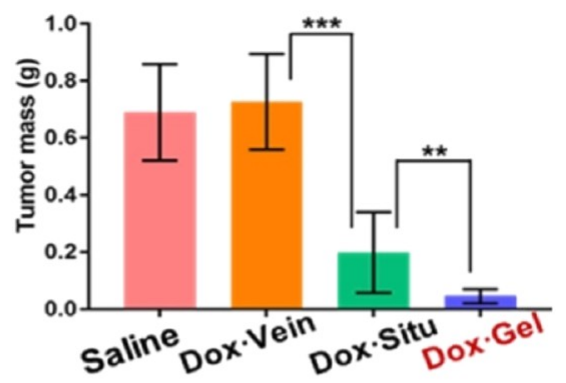

e

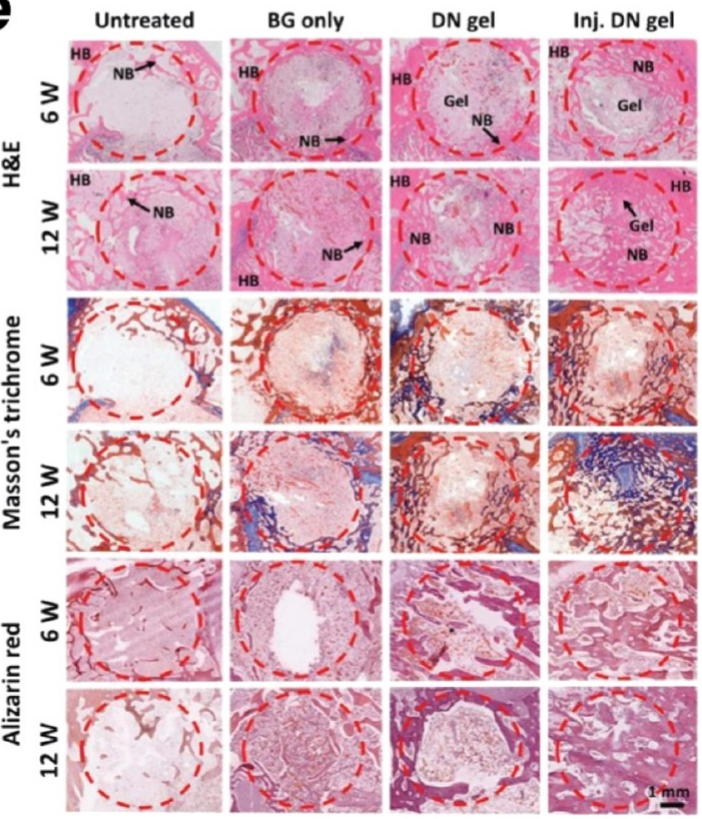

Figure 9. (a) Fluorescent imaging and (b) weight after resection of a fluorescently labeled human tumor in a mouse model shows that a DOXloaded injectable double-network hydrogel slows tumor growth. The performance of in situ formed (c1) BG-loaded PVA gel (PVA/BG gel), (c2) PVA/PEG gel, and (c3) PVA/BG DN gel against compression. (c) Demonstration of the toughness of in situ formed PVA/BG DN hydrogel (containing 10\% BG) by knotting and then unhitching (bottom images). (d) Microcomputed tomography (micro-CT) image of the rabbit joints after treatment for 6 and 12 weeks. The PVA/BG DN gel contained 40\% PEG and 20\% BG particles. Red circles represent the projection of the defects, representing a diameter of $5 \mathrm{~mm}$. The bottom images are the top view and side view of the 3D constructed bone-like tissue in the defect site (green color). (e) Histopathological sections of bone defects left untreated or being treated by different formulations. The PVA/BG DN gel contained 40\% PEG and 20\% BG particles. Red circles represent the projection of the defects with a diameter of $5 \mathrm{~mm}$. HB means host bone, NB means new bone, and Gel describes the residual hydrogel piece. Panels a and $b$ adapted and reproduced with permission from ref 117 . Copyright 2019 American Chemical Society. Panels c-e adapted and reproduced with permission from ref 122. Copyright 2019 Wiley-VCH.

3.2. Dynamic/Dynamic Networks. 3.2.1. Dynamic Covalent. $\mathrm{Li}$ et al. described the development of conductive injectable hydrogels using gelatin grafted with polyaniline (GP). ${ }^{55,118}$ GP and carboxymethyl-chitosan (CMCS) were both cross-linked with oxidized dextran (OD), again via the Schiff-base reaction. Gelation occurred rapidly at $37{ }^{\circ} \mathrm{C}$. Polyaniline concentration was employed as a handle to modulate gelation time, swelling (70 to $140 \%$ ), storage modulus (924, 571, and $21 \mathrm{kPa}$ ) and pore size (75, 125, and $200 \mu \mathrm{m}$ ). The cross-linking degree decreased with increasing polyaniline content due to consumption of amine group on gelatin chains. The authors also studied the link between polyaniline content and $\mathrm{C} 2 \mathrm{C} 12$ myoblast and ADMSC cells. The hydrogels containing polyaniline led to enhanced cell proliferation, attributed to the myoblast cells responding to electrical stimulation. In vitro testing and subcutaneous implantation in rats were consistent with biocompatibility.
Despite the dynamic cross-linking strategy, shear-thinning or self-healing behavior was not reported.

Recently, Li et al. described using a single polymeric crosslinker to form the double-network hydrogels with two dynamic linkages, namely, imines and borate esters. ${ }^{117}$ First, benzaldehyde and phenylboronic acid groups were attached at either end of a PEG backbone to obtain a heterotelechelic multifunctional PEG (MF-PEG). Then, MF-PEG simultaneously reacted with poly(vinyl alcohol) (PVA) through the borate ester and glycol chitosan (GC) via an imine to generate a DN hydrogel at mild conditions $\left(\mathrm{pH} 7,25^{\circ} \mathrm{C}\right)$. The gelation time of different hydrogel formulations were tested and the results showed that a SN based on PVA gels faster $(2 \mathrm{~s})$ than SN of GC (100 s), consistent with the rapid formation of borate ester. The storage modulus $\left(G^{\prime}=1-6 \mathrm{kPa}\right)$ and mucoadhesive strength $(2-6 \mathrm{kPa})$ were higher than the constituent single networks. The dynamic nature of both network connectors endowed these hydrogels with self-healing 
and shear-thinning behavior, but the mechanical properties were inferior compared with conventional DNs having static covalent cross-linking. The biocompatibility of these hydrogels were tested in vitro ( $>80 \%$, human hepatoma cell line) and in vivo (mouse), suggesting that the hydrogels did not cause allergic reaction, inflammation, or cell toxicity. In addition, the authors tested the dynamic DN hydrogel as an injectable drug carrier (Figure 9a, b). Doxorubicin (Dox) was incorporated into the hydrogel followed by direct injection into a human tumor implanted in a mouse. The injectable hydrogel delivery of DOX led to enhanced suppression of tumor growth. The gradual release of DOX was attributed to the dynamic linkages.

Combining dynamic hydrazone and imine bonds was explored by Wang et al., whereby DN hydrogels were formed by reaction of aldehyde groups of oxidized alginate (OSA) with amino groups of gelatin (GE) and hydrazides of adipic acid dihydrazide $(\mathrm{ADH}) .{ }^{119}$ The novelty of this work lies with the macroporous structure generated via high-speed shearing, which was reported to facilitate cellular infiltration and nutrient diffusion. The double dynamic cross-linking significantly enhanced the storage modulus (between $\sim 15$ and $\sim 55 \mathrm{kPa}$ ) compared to single networks (between $\sim 0.18$ and $\sim 0.60 \mathrm{kPa}$ ). This improvement is comparable to hydrogels having (static) chemical cross-links. The dynamic linkages endow hydrogels with self-healing and injectability, demonstrated by rheology tests. The water uptake (ca. 400\%), degradation rate (around $70 \%$ remaining weight) and mechanical properties of hydrogels could be tuned by polymer concentration and hence crosslinking degree. Considering both the structure and chemical features of the material design, the authors developed macroporous injectable hydrogels with good biocompatibility and the capacity of cell/drug loading. Sustained release of a growth factor (HEGF) was observed, and in vivo subcutaneous injection studies showed controllable inflammatory and toxic responses in rat models.

3.2.2. Dynamic Covalent/lonic. Injectable DN hydrogels have also been reported by combining dynamic covalent crosslinking and ionic bonding. ${ }^{124}$ Yang et al. described a first network formed via dynamic covalent bonding between glycol chitosan (GC) and dibenzaldehyde-PEO and a second network cross-linked by electrostatic interactions between calcium ions $\left(\mathrm{Ca}^{2+}\right)$ and alginate. As expected, polymer concentration and cross-linking type strongly influenced gelation times and thus injectability. Sol-gel transition of alginate network (ionic cross-linking, $2 \mathrm{~min}$ ) was faster than that of the glycol chitosan network (DCvC, $4 \mathrm{~min}$ ). However, the DN hydrogels $(3 \mathrm{~min})$ showed gelation time values between both SN suggesting that the ionic network drives the sol-gel transition. Syringe injection was possible to make various scaffold constructs (Figure 10a). The fracture energy of $\mathrm{DN}\left(416 \mathrm{~J} / \mathrm{m}^{2}\right)$ and $\mathrm{SN}\left(\sim 40 \mathrm{~J} / \mathrm{m}^{2} \mathrm{GC}, \sim 240 \mathrm{~J} / \mathrm{m}^{2} \mathrm{Alg}\right)$ was consistent with energy dissipation via disruption of ionic bonding during compressive strain (Figure 10b). Importantly, the fracture energy of these DNs is in the range of cartilage (1 $\times 10^{2}$ to $\left.1 \times 10^{3} \mathrm{~J} / \mathrm{m}^{2}\right)$. Antifatigue behavior of the $\mathrm{DN}$ hydrogels was also remarkable ( $>100$ cycles), showing that the dynamic cross-linking strategy allows excellent cross-link recovery after deformation. Biocompatibility was verified by both in vitro and in vivo tests; extensive tissue damage was not observed after the subcutaneous injection of DN hydrogels into $\mathrm{BALB} / \mathrm{c}$ mice.

In a follow-up, the same authors investigated the potential application of the DN hydrogel for bone tissue regeneration a

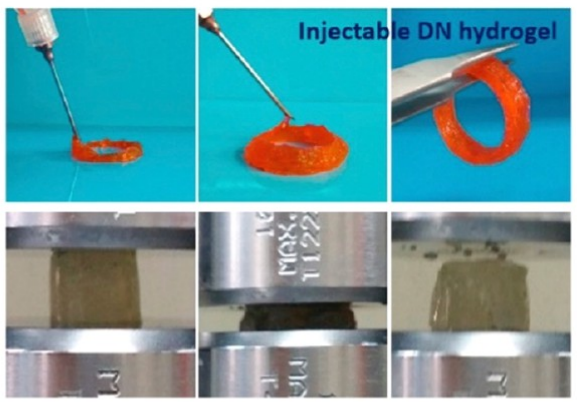

b

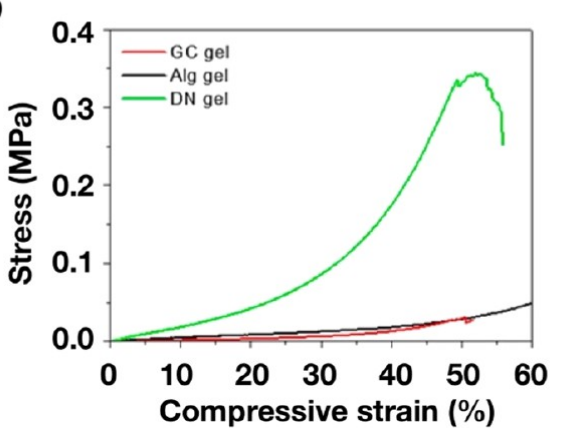

Figure 10. (a) Injection and compression photographs of dual networks comprising chitosan/PEO and alginate and (b) compressive stress-strain measurements on the dual networks and corresponding single networks. Adapted and reproduced with permission from ref 124. Copyright 2017 American Chemical Society.

focused on promoting rapid vascularization. ${ }^{125}$ The authors observed enhanced vascularization and osteogenesis upon encapsulating vascular endothelial and bone marrow mesenchymal stem cells into the DN hydrogels. These properties were attributed to the direct coculture in dynamic DN hydrogel due to cell-cell communication both in vitro and in vivo. The reversibility of the cross-links (imine bonding and ionic interactions) favors cell-to-cell connection during cell proliferation, promoting the angiogenic and osteogenic differentiation of the stem cells. These reports suggest that both double-network and dynamic cross-linking strategies are essential to mimic the ECM properties enhancing cell communication.

3.2.3. Dynamic Covalent/H Bond and VDW (Thermogelling). Abandansari et al. prepared DN hydrogels by combining slow Diels-Alder chemistry with fast thermoresponsive cross-linking to modulate both gelation time and mechanical properties. ${ }^{19}$ The first network was rapidly formed (1 $\mathrm{min})$ through hydrophobic interaction of pluronic segments of P127-grafted chitosan at $37{ }^{\circ} \mathrm{C}$ and the second network was formed more slowly $(2 \mathrm{~h})$ through Diels-Alder reaction between maleimide groups of bimaleimide-PEG and furan groups of furan-modified gelatin. The storage and compressive modulus of $\mathrm{DN}$ hydrogels ( $\sim 1$ and $\sim 40 \mathrm{kPa}$, respectively) were similar to SN suggesting that the DN strategy did not appreciably improve the mechanical properties. However, the combined mechanical, self-healing and thermoresponsive gel properties did allow injectability and high gel retention at the injection site. In addition, high in vitro cell viability (>95\%), high in vivo cell retention, and survival as well as a marked vascularization observed at harvested cell-laden DN provides promising potential for cell therapy and tissue engineering. 

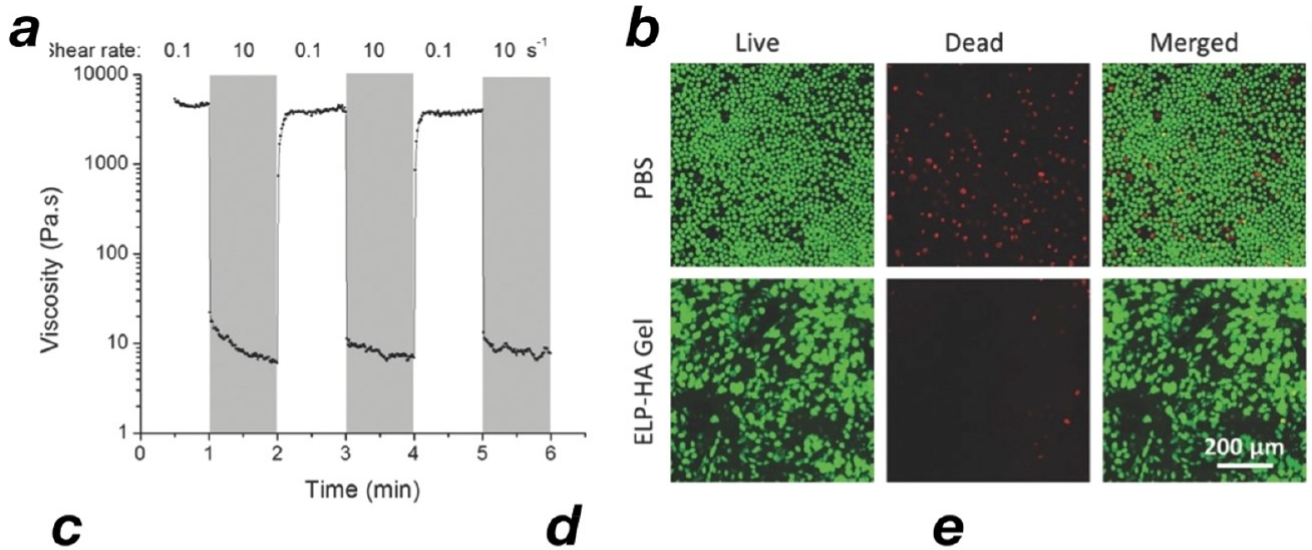

C

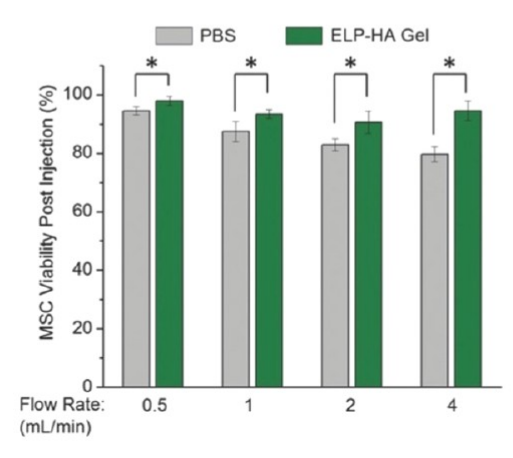

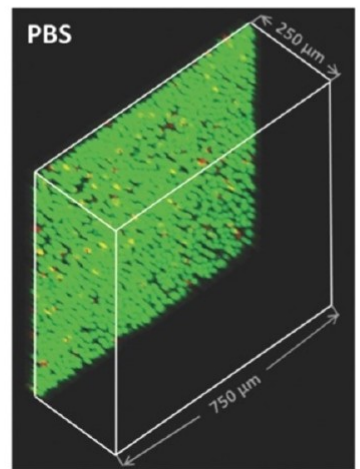

e

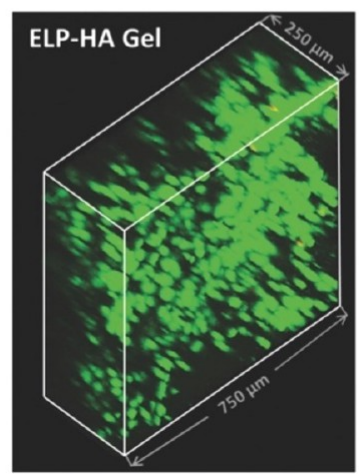

Figure 11. ELP-HA-based dual-network injectable hydrogels show (a) self-healing and suitability for injection and delivery of MSCs. Notably, the ELP-HA hydrogels show (b, c) higher cell viability (when compared to PBS injection) and (d, e) better 3D cell distribution. Adapted and reproduced with permission from ref 126. Copyright 2017 Wiley-VCH.

Cho and Ooya also proposed a double network by combining thermo-gelling and dynamic covalent cross-linked networks using a biopolymer (agar) with thermosensitive properties to form the physical cross-linked network. ${ }^{127}$ Thus, the first network was formed via hydrogen bonding at $37{ }^{\circ} \mathrm{C}$ and the second network was obtained through Schiff-base reaction between glycol chitosan (GC) and oxidized carboxymethyl cellulose. The DN gels possessed improved swelling and mechanical properties compared to the corresponding SN. However, the DN properties were merely the sum of the properties of the two components. The stressstrain curves of DN and SN were similar, yet the DN did show the highest fracture strain of all samples. The dynamic covalent cross-linking provided antifatigue and self-healing performance. The loading-unloading tests at strain of $50 \%$ indicated minimal hysteresis (5 cycles). Both DN and SN showed high cell viability ( $\sim 100 \%$, fibroblasts), whereas $\mathrm{DN}$ hydrogel prevented cell aggregation, as was observed on GC SN. The physical and DCvC network provides these gels with potential application for protein immobilization, drug/cell delivery, and tissue engineering.

A different strategy was proposed by Wang et al. ${ }^{126}$ In this case, the double network also involved physical (thermogelling) and dynamic covalent linkages. However, a single multifunctional polymer generated both physically and chemically cross-linked networks. The novelty of this approach was the molecular design of thermoresponsive cell-adhesive protein (elastin like protein, ELP) including thermoresponsive and enzymatic degradable sequences and lysine units for further modification with hydrazine groups (ELP-HYD). The hydrazine groups of ELP-HYD reacted with aldehyde groups of hyaluronic acid (oxidized HA) to form the first network. The second network was formed by protein folding (hydrogen bonds and hydrophobic interactions). In this approach, the dynamic covalent cross-linking reaction (10 s) was faster than thermo-gelation $(5 \mathrm{~min})$. Rheological testing was used to evaluate the DN hydrogel performance. The first network led to increased storage modulus $(\sim 1 \mathrm{kPa})$ compared to $\mathrm{SN}$ gels (around $0.001 \mathrm{kPa}$ ), whereas toughening arose from the second physical cross-linking. Further, thermoresponsive stiffening improved with increasing ELP-HYD content. However, the storage modulus of DN hydrogels were not compared with the singly cross-linked networks to corroborate the dual-network effect. Shear-thinning and self-healing properties were observed in DN due to the dynamic nature of the hydrazone bonding (Figure 11a). Erosion rate decreased markedly in the DN gels, with the mass remaining going from $1 \%$ (SN based on HA-ALD) to $80 \%(\mathrm{DN})$ at day 9. The in vitro studies of the MSC cell-laden DN hydrogel showed a high cell viability and differentiation potential postinjection, with a protective effect of the hydrogel when compared to PBS injection (Figure 11b-d).

As noted in the many of the previous examples, the doublenetwork strategy plays a key role in attenuating degradation rates to facilitate application at physiological conditions. The expected synergistic effect on the mechanical properties was not routinely observed by combining dynamic covalent linkages and thermo-gelling polymer. However, the dynamic nature of these cross-linking provided appealing properties such as shear-thinning, self-healing, and injectability. Notably, the dynamic nature of the cross-linking in this class of DN hydrogels can also provide cell protection from the 

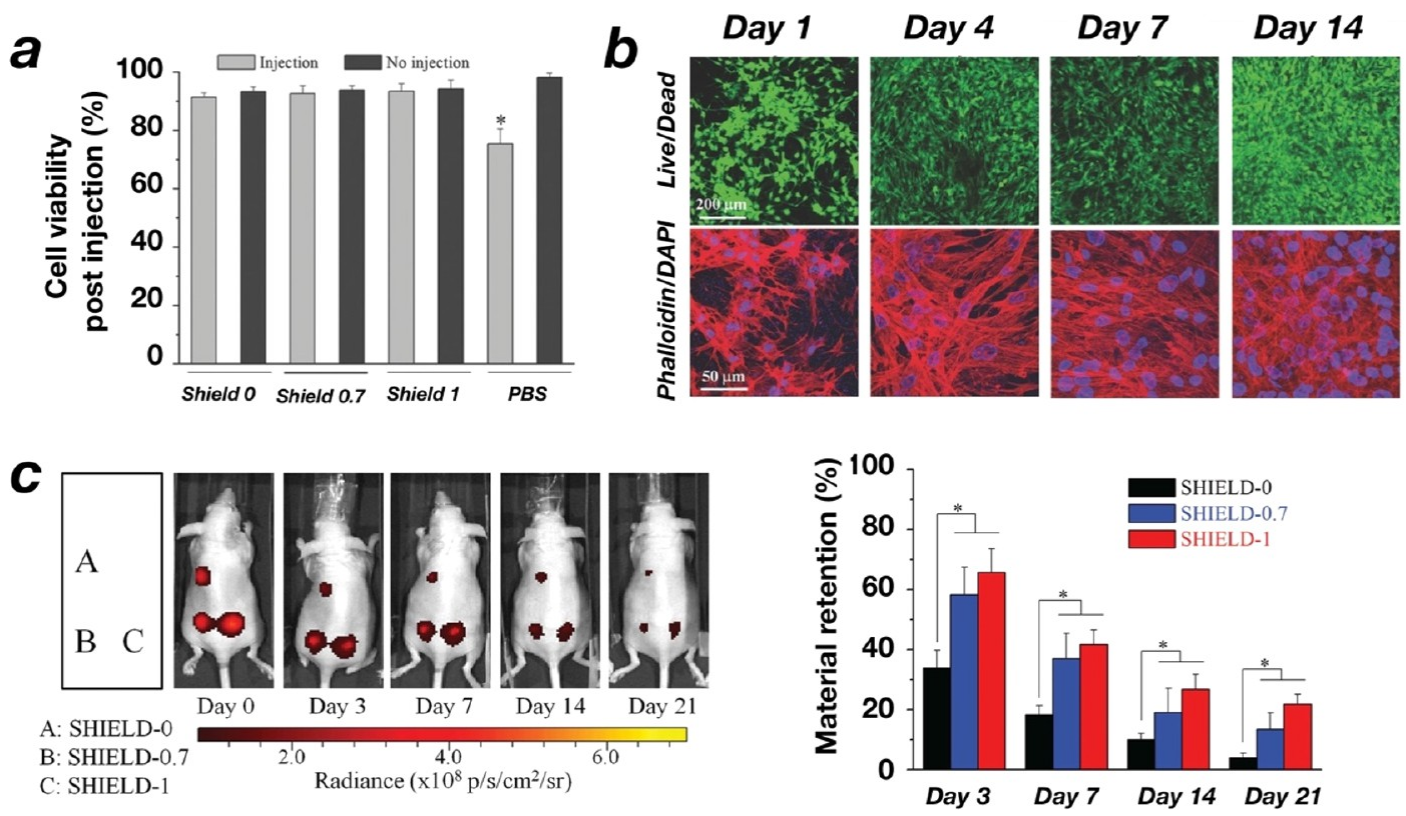

Figure 12. Dual-network SHIELD hydrogels show cell protective properties with (a) enhanced viability of hACSs immediately after injection and (b) up to 14 days post injection. The SHIELD hdyrogels also showed (c) higher material and cell retention after subcutaneous injection in a mouse model. Adapted and reproduced with permission from ref 121. Copyright 2015 Wiley-VCH.

mechanically disruptive forces experienced during injection, and as such may be critical for applications in tissue engineering.

Thermoresponsive Pluronic 127 was also explored by $\mathrm{Qu}$ et al. to form double-network hydrogels. ${ }^{128}$ This commercial triblock copolymer was functionalized with benzaldehyde end groups (P127-CHO), which could react with amine groups of quaternized chitosan (QCS). Thus, P127 self-assembles via hydrophobic interactions into micelles in water and reacts rapidly (<90 s) with QCS to form one hybrid physically chemically cross-linked double network. Hydrogels were prepared with 2 wt $\%$ chitosan and different amount of P127-CHO (between 14.4 and 24.0\%). The mechanical (Young's modulus up to $37.3 \mathrm{kPa}$ ) and rheological ( $G^{\prime}$ up to $53 \mathrm{kPa}$ ) properties of hydrogels were similar to skin tissue. The authors demonstrated that hydrogels have stretchable, compressible, shear-thinning, self-healing and recoverable mechanical properties. These properties were attributed to the combination of dynamic Schiff-base (covalent bonds) and micelle hydrophobic interactions (physical cross-linking), which are reversible linkages that provide a source of energy dissipation. Due to the potential application of the hydrogels as skin wound healing dressing, further characterization and drugloaded hydrogels were performed. Curcumin-loaded hydrogels demonstrated good antibacterial properties, in vivo clotting capacity, wound healing rate, granulation tissue thickness, and collagen disposition.

Dual cross-linking with hydrazone and hydrogen bonds to form injectable hydrogels has recently been reported. ${ }^{129,130}$ Wang et al. developed a thermo-gelling hydrogel based on hydrazide-functionalized PNIPAM, oxidized dextrin and poly(N-acryloyl glycinamide) (PNAGA). ${ }^{130}$ Two preforming solutions were mixed in situ using a dual syringe and the hydrogel was formed at physiological conditions by hydrophobic interactions (PNIPAM), hydrogen bonds (PNAGA), and hydrazone linkages (PNIPAM and oxidized dextrin). The storage modulus increased with increasing PNAGA content (second network, up to $517 \mathrm{kPa}$ ) according to rheological measurements. This improvement of mechanical properties is likely due to the higher polymer concentration and hence higher cross-linking degree. However, the second network clearly enhanced the stability of the hydrogel. The thermoresponsive behavior of hydrogel was also assessed as means for controlling the release of a model drug (propranolol hydrochloride).

Guo et al. developed a physically chemically cross-linked hydrogel based on poly(acrylamide-co-diacetone acrylamide) (PAAm-co-DAAm), PVP, and adipic acid dihyadrazide $(\mathrm{ADH}) .{ }^{129}$ PAAm-DAAm reacted with $\mathrm{ADH}$ to form hydrazone bonds (first cross-linking) and interacted with PVP by hydrogen bonds (second cross-linking). In this case, the combination of the two dynamic cross-linking moieties enhanced the mechanical properties of hydrogels $(\mathrm{YM} \sim 350$ $\mathrm{kPa})$ compared with corresponding single cross-linked systems $(\mathrm{YM} \sim 6$ and $33 \mathrm{kPa})$. The hydrogels also exhibited impressive self-healing rapid self-recovery. Because of the $\mathrm{pH}$-responsiveness of hydrazone groups, the mechanical and rheological properties were also tested at $\mathrm{pH} 2$ and 6 . The authors suggested that the biocompatible ( $>80 \%$ cell viability) injectable hydrogels have potential applications in hard tissue. However, the application of these materials as injectable hydrogels may be limited because of the tedious fabrication method proposed. This method involved two steps: the first one is the free-radical copolymerization of AAm and DAAm (under a nitrogen atmosphere, $3 \mathrm{~h}$ ), followed by curing in molds for $6 \mathrm{~h}$ at $40{ }^{\circ} \mathrm{C}$.

3.2.4. $H$ Bond and VDW. Researchers also assessed fully physically cross-linked double networks as injectable hydrogels, using [body] temperature to trigger gelation of thermoresponsive polymer.

Cai et al. proposed a molecular design of a thermoresponsive copolymer with polypeptide domains to form the double network. ${ }^{121}$ The authors synthesized a copolymer (Pep1-PEGPNIPAm) by conjugation of poly (N-isopropylacrylamide) and 
a

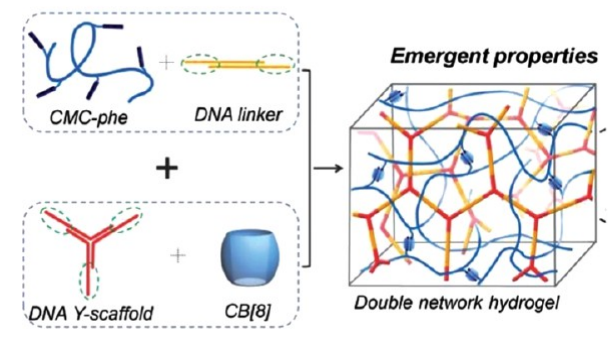

b

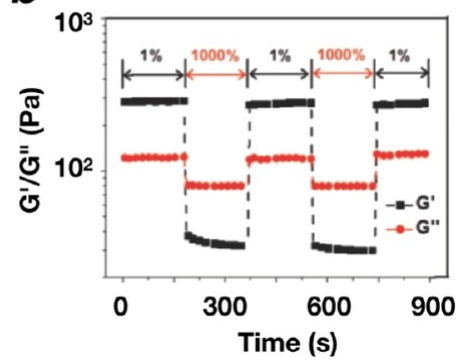

Figure 13. (a) Schematic preparation of dual-network hydrogels from DNA and host-guest networks; (b) shear thinning behavior demonstrated with alternating strains of $\%$ and $1000 \%$. Adapted and reproduced with permission from ref 123 . Copyright $2015 \mathrm{Wiley}-\mathrm{VCH}$.

star-shaped peptide-polyethylene glycol. In this dual-network approach named SHIELD, the first physical network was formed by the molecular recognition between the peptide of Pep1-PEG-PNIPAm and the engineered recombinant protein C7. The second network then formed via thermal phase transition of the PNIPAm segments. The storage modulus initially increased to $13 \mathrm{~Pa}$ after mixing both polymers (copolymer and $\mathrm{C} 7$ ) at $25^{\circ} \mathrm{C}$ and then to $100 \mathrm{~Pa}$ after heating to $37{ }^{\circ} \mathrm{C}$ as LCST of PNIPA. The mechanical properties were modulated by adjusting the relative PNIPA content. The degradation of DN was significantly slower than SN (Pep1-PEG and C7); the hydrogel erosion was around $70 \%$ at day 14 . These results suggests that protein interactions as physical linkages in one of the networks are too weak for substantial improvements in the mechanical properties. As highlighted in the previous examples, the combination of dynamic covalent cross-linking with a thermo-gelling polymer typically improved the stability of DN hydrogels. Accordingly, the type of cross-linking plays a key role in determining the hydrogel properties within the general double-network strategy. Nevertheless, the fully physically cross-linked DN hydrogel demonstrated self-healing, shear-thinning, and cellprotective properties during injection because of the reversibility of linkages on the networks (Figure 12a, b). In vitro and in vivo studies corroborated a high cell viability (>90\% hASC) and an enhanced cell retention at the desired site (Figure 12c).

Liu and Yao proposed a double network based on two thermoresponsive biopolymers. ${ }^{120}$ The transition temperature (i.e., LCST) of methyl-cellulose (MC) and xanthan gum (XG) aqueous solutions is approximately $40-50{ }^{\circ} \mathrm{C}$, where both polysaccharides undergo conformational transitions but only MC exhibits a sol-gel transition. The rheological characterization was consistent with both XG and MC contributing to the amplified mechanical strength. As previously discussed, these DN hydrogels based solely on physical cross-linking also failed to synergistically improve the mechanical properties. The authors demonstrated that tuning XG and MC concentration enabled modulation of mechanical properties $\left(G^{\prime} \approx 1 \mathrm{kPa}\right)$, sol-gel transition temperature (between 28 and $37^{\circ} \mathrm{C}$ ), and gelation time (between 30 and $180 \mathrm{~s}$ ). Because of reversible physical interactions within the XG network, the DN hydrogel possessed excellent thixotropic recovery. Chemical characterization (FTIR, XRD, CD) revealed that neither XG nor MC affected each other in terms of ordered structure. The DN hydrogel exhibited similar erosion rate and swelling to the corresponding SN. In vitro and in vivo studies demonstrated biocompatibility and biodegradability. In addition, a drug (doxorubicin DOX) was loaded into DN hydrogel and sustained release was observed, corroborating the potential application of XG/MC blend as an injectable hydrogel for long-term drug delivery.

3.2.5. H Bond/Host-Guest Supramolecular. To regulate cross-link dynamics and response to external stimuli, researchers have explored host-guest supramolecular interactions to form double-network hydrogels. $\mathrm{Li}$ and co-workers proposed a supramolecularly assembled double network: one through DNA hybridization and the other by host-guest interactions of cucurbit $[8]$ uril $(\mathrm{CB}[8])$ and phenylalaninefunctionalized carboxymethyl cellulose (CMC-phe). ${ }^{123}$ The novelty of this approach is that two orthogonal recognition processes led DN hydrogel formation. First, a DNA network was formed by hydrogen bonds of two complementary sequences on a DNA Y scaffold and a DNA linker. The second recognition process then takes place between CMCphe and $\mathrm{CB}[8]$, attributed to the host-guest interaction, to form the second network (Figure 13a). This is one of the few works where the authors achieved to demonstrate the synergetic effect of the double physical network on the mechanical properties of hydrogel. The storage modulus (281 $\mathrm{Pa}$ ) of the $\mathrm{DN}$ was higher than that of the corresponding single network and even the sum of the two single networks. The improvement on $G^{\prime}$ was not as high as the chemically crosslinked DN could achieve because of the weaker binding that can be easily sheared under stress (Figure 13b).

3.2.6. Ionic/H Bond. In a recent report, Zhao and coworkers proposed a physical cross-linked double-network hydrogel containing bioglass. ${ }^{122}$ To mimic the osseous structures, which are composed of inorganic and organic networks with water and cells, the authors developed composite DN hydrogels. Poly(ethylene glycol) (PEG) and BG rapidly formed the first network by hydrogen-bonding interactions. 4-carboxy-phenylboronic acid reacts first with poly(vinyl alcohol) (PVA) to form borate ester (dynamic covalent cross-linking) and then the carboxylic groups of CPBA interact with calcium ions to form the second network. Because both reactions occurred quickly $(<60 \mathrm{~s})$, a dual syringe was used to form hydrogel in situ. Although DN hydrogels showed higher compressive modulus $(\sim 2.7 \mathrm{MPa})$ and fracture energy $\left(\sim 63 \mathrm{~kJ} / \mathrm{m}^{2}\right)$ than the corresponding SN hydrogel, this improvement is less than expected for a doublenetwork strategy. Nevertheless, this strategy allowed for combining the properties of both networks: lower degradation rate and toughness and higher fracture energy of the PVA network and bioactivity of BG (promoting mineralization). In addition, the composite DN hydrogels showed good injectability, biocompatibility, and osteogenicity, resulting in promising injectable load-bearing scaffold for treating femoral 
supracondylar bone defect (Figure 9c-e). The high compressive modulus observed for this DN hydrogel compared to the other physically cross-linked network is likely due to the high polymer concentration (40 wt \% PEG/20 wt \% BG/7 wt $\%$ PVA).

3.3. Static/Static Networks. The combination of two static networks is not attractive for injectable hydrogels. The fabrication of two chemically cross-linked networks independently after injection is difficult, whereas the absence of any network prior to injection often means either a low viscosity solution or a poorly thinning high viscosity solution.

Although one can consider disulfides dynamic covalent cross-links, their use in the following hydrogel shows one of the closest double networks by covalent bond formation to date. Zhang et al. proposed an injectable hydrogel based on fibrin (F) and hyaluronic acid (HA). ${ }^{131}$ An HA derivative was first synthesized bearing thiol and 2-dithiopyridyl groups, and then mixed with fibrinogen to fabricate the double networks with disulfide cross-linking. High hydrophilicity of HA prevents compaction of the fibrin network, whereas fibrin provides an adhesive environment for in situ encapsulated cells. DN showed an increased stiffness and lower degradation rate compared to the single fibrin network. In addition, the authors tested the cell viability and proliferation of MG63 cells encapsulated into hydrogels. The results showed that DN enhanced cell proliferation compared to SN hydrogels, and the DN structure favored the cell spreading.

\section{FUTURE PERSPECTIVE}

Since Gong et al. introduced the concept of double-network gels, many researchers have applied this fabrication strategy to develop gels with high mechanical performance that can be tailored to mimic a wide variety of load-bearing biological tissues. ${ }^{16}$ At the beginning, the gels were called DN when two individual chemically cross-linked networks were synthesized. The enhanced mechanical properties result in the interpenetration of two networks with contrasting physical properties: one network is rigid and the other is soft and ductile. In the last years, the use of fully or partially chemically cross-linked double networks have shifted to the partially or fully physical cross-linked double networks because of the relevant properties of dynamic linkages for biomedical applications. The mechanical properties play a key role according to the application; both bioprinting and injectable hydrogel applications require viscoelastic hydrogels. Indeed, most of the research works explored at least one dynamic cross-linking to create the double network. Among the dynamic cross-linking, we found both physical interactions (i.e., ionic and hydrophobic interactions, hydrogen bonds) and dynamic covalent (e.g., hydrazone, imine, oxime, borate ester bonds) cross-linking.

One can quickly see the large number of double-network systems developed for injectability, which with proper modifications can be ported into 3D printing. Both fields can leverage their knowledge to create formulations that are more advanced. Furthermore, one can notice the abundance of dynamic/dynamic networks used for injectable hydrogels, whereas few examples exist for $3 \mathrm{D}$ printing. Admittedly, the challenges to get enhanced mechanical properties and process stability with dynamic networks remain, yet the use of dynamic/dynamic hydrogels in $3 \mathrm{D}$ printing is well primed for exploration.
The concept of double networks has been broadening in the past decade. ${ }^{17,18}$ After the first approaches with two individually cross-linked networks, double networks have been designed using two cross-linking to form one only network combining two or more polymers. As previously mentioned, some examples of these $\mathrm{DN}$ hydrogels have shown enhanced erosion and mechanical properties; however, this improvement is not extremely higher than that of the two independently cross-linked double networks. In addition, these DN hydrogels, with one network combining two cross-links, are similar to dual cross-linked hydrogels found in the literature. Some examples of dual cross-linking networks also showed enhanced mechanical and injectability properties. ${ }^{132-135}$ Therefore, there is a necessity to define each system and what properties are expected with each material design.

\section{CONCLUSION}

The complexity of native tissues in terms of composition, spatiotemporal arrangement, and performance presents a challenging target for regenerative medicine. Native tissues exhibit an optimized balance between strength, resilience, and mobility of the vehicles responsible for intercellular communication and repair. Nevertheless, development of novel synthetic and hybrid structures has already led to discoveries that approach the sophistication of native tissues. New challenges emerge when combining the complex behavioral features that are routinely designed into biomedical devices with convenient delivery strategies or contemporary fabrication techniques. More specifically, delivering complex hydrogel formulations via syringe is difficult, particularly when competing sets of properties are required before/during and after delivery. Gels must adequately flow through a syringe or catheter, whereas upon reaching the target site the structures should possess mechanical integrity that allows sustained functionality in the new environment. Likewise, bioprinting technologies typically relies on free-flowing precursors as bioinks for high-resolution structures to be attained. However, after printing, the structures should be transformed into highstrength structures capable of withstanding various deformation forces while simultaneously facilitating anatomically accurate tissue formation.

The field has witnessed some important breakthroughs within the context of attaining such complex behavior. Employing multiple networks carries the advantage of imparting a range of properties, while typically enhancing the mechanical properties. Many cross-linking strategies exist to adapt to various on-demand transitions is physical properties required in injection and printing. Hurdles still exist. For example, few papers address both biocompatibility and mechanical properties; fewer are able to take forward these novel materials toward complex tissue formation. This makes comparisons between different publications and systems difficult and suggests that finding the right balance is not straightforward. However, there are some inspiring examples presented here that provide valuable guiding principles to further develop the field.

We predict that multicomponent (dual network, IPN, double network, etc.) hydrogels will play an important role in the tissue engineering field moving forward. The native ECM of cells is inherently complex and consists of multiple macromolecular networks interacting in a dynamic fashion for a responsive and instructive environment around tissues and 
cell. Replacing this complexity with a single component or single-network hydrogel remains highly unlikely. As we move forward toward creating better synthetic ECM mimics, rational design of hydrogel formulation via complex (not complicated) macromolecular systems and design is an attractive way forward. As with any field, increases in complexity come with new hurdles, yet also new potential for innovation and understanding.

In addition to being more biomimetic, multinetwork hydrogels also have many practical advantages. Combining both dynamic bonding and irreversible/covalent bonding offers advantages in terms of impressive mechanics and selfhealing attributes. Likewise, functionality is readily incorporated into dual networks bearing receptors for proteins, for example. Many networks used in the examples here are also biocompatible. One of the keys in applying DN hydrogels in printing and injection applications lies in endowing the materials with shear-thinning behavior. A deeper understanding of network topology, chemical functionality, and cell viability in shear-thinning systems is providing momentum in the field.

Many of the 3D printing examples shown within this review are based on straightforward extrusion of these multicomponent double-network hydrogels. Recently, significant advances in biofabrication and bioprinting methodologies have led to the ability to create more complex, multimaterial, highresolution, and gradient type structures with greater accuracy and speed. Straightforward approaches like gel-in-gel or bath bioprinting allows enhanced resolution and allows for broader materials properties in extrusion-based approaches. Furthermore, when it comes to multinetwork printing, the baths could be leveraged for triggering the formation of the second network (e.g., the addition of $\mathrm{Ca}^{2+}$ as with alginate). These more advanced extrusion set-ups are well poised for use with double-network hydrogels. Light-based techniques like digital light processing (DLP), volumetric, and holographic (bio) printing of hydrogels allows rapid construction of complex 3D objects via light-initiated cross-linking. These new techniques have mostly employed single component hydrogels (e.g., PEGDA, GelMA) in early studies, yet should find use with more complex materials in years to come. With doublenetwork hydrogels, a significant hurdle is always the practicalities in forming two separate networks. Conceptually, yet challenging, would be to initiate both networks via different wavelengths of light; practically, the second network could be formed post printing. As an intermediate approach, marrying a light-initiated network with a thermoreversible (near $37^{\circ} \mathrm{C}$ ) or a dynamically cross-linked network may provide an uncomplicated approach in the near future.

Furthermore, extending the trajectory beyond printing and injection of dual-network systems is important to make headway. For example, moving from cell-viability studies to investigating tissue regeneration capabilities and ultimately degradation and expulsion from the body are critical points in the process, yet do take time and advanced studies. Dualnetwork systems provide a great deal of flexibility in design. Incorporating all of these aspects into a single system, while challenging, is coming well within reach. On the basis of the collective results from the research summarized in this review, there is tremendous promise for this field and we are eagerly looking forward to see what the coming years have in store.

\section{AUTHOR INFORMATION}

\section{Corresponding Authors}

Louis M. Pitet - Advanced Functional Polymers Group, Department of Chemistry, Institute for Materials Research (IMO), Hasselt University, 3500 Hasselt, Belgium; 다이.org/0000-0002-4733-0707; Email: louis.pitet@ uhasselt.be

Matthew B. Baker - Department of Complex Tissue Regeneration, MERLN Institute for Technology-Inspired Regenerative Medicine, Maastricht University, $6211 \mathrm{LK}$ Maastricht, The Netherlands; (1) orcid.org/0000-00031731-3858; Email: m.baker@maastrichtuniversity.nl

\section{Authors}

Ana A. Aldana - Department of Complex Tissue Regeneration, MERLN Institute for Technology-Inspired Regenerative Medicine, Maastricht University, 6211 LK Maastricht, The Netherlands

Sofie Houben - Advanced Functional Polymers Group, Department of Chemistry, Institute for Materials Research (IMO), Hasselt University, 3500 Hasselt, Belgium; (1) orcid.org/0000-0003-1056-0223

Lorenzo Moroni - Department of Complex Tissue Regeneration, MERLN Institute for Technology-Inspired Regenerative Medicine, Maastricht University, 6211 LK Maastricht, The Netherlands; (1) orcid.org/0000-00031298-6025

Complete contact information is available at:

https://pubs.acs.org/10.1021/acsbiomaterials.0c01749

\section{Author Contributions}

${ }^{\dagger}$ A.A.A. and S.H. have contributed equally to this work. Notes

The authors declare no competing financial interest.

\section{ACKNOWLEDGMENTS}

L.M.P., A.A.A., and M.B.B. are grateful for financial support from the Research Foundation-Flanders (FWO) under contract G080020N. S.H. is grateful for funding from a BOF-OWB mandate under contract BOF19OWB08. A.A.A., L.M., and M.B.B. acknowledge NWO for funding via the project "DynAM" under project agreement 731.016.202. M.B.B. and L.M. also acknowledge the Province of Limburg for support and funding.

\section{REFERENCES}

(1) Ng, W. L.; Chua, C. K.; Shen, Y.-F. Print Me An Organ! Why We Are Not There Yet. Prog. Polym. Sci. 2019, 97, 101145.

(2) Ooi, H. W.; Hafeez, S.; van Blitterswijk, C. A.; Moroni, L.; Baker, M. B. Hydrogels that listen to cells: a review of cell-responsive strategies in biomaterial design for tissue regeneration. Mater. Horiz. 2017, 4, 1020-1040.

(3) Moroni, L.; Burdick, J. A.; Highley, C.; Lee, S. J.; Morimoto, Y.; Takeuchi, S.; Yoo, J. J. Biofabrication strategies for 3D in vitro models and regenerative medicine. Nat. Rev. Mater. 2018, 3, 21-37.

(4) Mota, C.; Camarero-Espinosa, S.; Baker, M. B.; Wieringa, P.; Moroni, L. Bioprinting: From Tissue and Organ Development to in Vitro Models. Chem. Rev. 2020, 120, 10547-10607.

(5) Aldana, A. A.; Malatto, L.; Rehman, M. A. U.; Boccaccini, A. R.; Abraham, G. A. Fabrication of Gelatin Methacrylate (GelMA) Scaffolds with Nano- and Micro-Topographical and Morphological Features. Nanomaterials 2019, 9, 120.

(6) Rivero, G.; Aldana, A. A.; Frontini Lopez, Y. R.; Liverani, L.; Boccacini, A. R.; Bustos, D. M.; Abraham, G. A. 14-3-3epsilon 
protein-immobilized PCL-HA electrospun scaffolds with enhanced osteogenicity. J. Mater. Sci.: Mater. Med. 2019, 30, 99.

(7) Yao, T.; Wieringa, P. A.; Chen, H.; Amit, C.; Samal, P.; Giselbrecht, S.; Baker, M. B; Moroni, L. Fabrication of a selfassembled honeycomb nanofibrous scaffold to guide endothelial morphogenesis. Biofabrication 2020, 12, 045001.

(8) Yao, T.; Baker, M. B.; Moroni, L. Strategies to Improve Nanofibrous Scaffolds for Vascular Tissue Engineering. Nanomaterials 2020, 10, 887 .

(9) Nawroth, J. C.; Scudder, L. L.; Halvorson, R. T.; Tresback, J.; Ferrier, J. P.; Sheehy, S. P.; Cho, A.; Kannan, S.; Sunyovszki, I.; Goss, J. A.; Campbell, P. H.; Parker, K. K. Automated fabrication of photopatterned gelatin hydrogels for organ-on-chips applications. Biofabrication 2018, 10, 025004.

(10) Hribar, K. C.; Choi, Y. S.; Ondeck, M.; Engler, A. J.; Chen, S. Digital Plasmonic Patterning for Localized Tuning of Hydrogel Stiffness. Adv. Funct. Mater. 2014, 24, 4922-4926.

(11) Morgan, F. L. C.; Moroni, L.; Baker, M. B. Dynamic Bioinks to Advance Bioprinting. Adv. Healthcare Mater. 2020, 9, No. e1901798.

(12) Weems, A. C.; Perez-Madrigal, M. M.; Arno, M. C.; Dove, A. P. 3D Printing for the Clinic: Examining Contemporary Polymeric Biomaterials and Their Clinical Utility. Biomacromolecules 2020, 21, 1037-1059.

(13) Sun, W.; Starly, B.; Daly, A. C.; Burdick, J. A.; Groll, J.; Skeldon, G.; Shu, W.; Sakai, Y.; Shinohara, M.; Nishikawa, M.; Jang, J.; Cho, D. W.; Nie, M.; Takeuchi, S.; Ostrovidov, S.; Khademhosseini, A.; Kamm, R. D.; Mironov, V.; Moroni, L.; Ozbolat, I. T. The bioprinting roadmap. Biofabrication 2020, 12, 022002.

(14) Vyas, D.; Udyawar, D. A Review on Current State of Art of Bioprinting. In $3 D$ Printing and Additive Manufacturing Technologies 2019, 195-201.

(15) GhavamiNejad, A.; Ashammakhi, N.; Wu, X. Y.; Khademhosseini, A. Crosslinking Strategies for 3D Bioprinting of Polymeric Hydrogels. Small 2020, 16, 2002931.

(16) Gong, J. P.; Katsuyama, Y.; Kurokawa, T.; Osada, Y. Doublenetwork hydrogels with extremely high mechanical strength. Adv. Mater. 2003, 15, 1155-1158.

(17) Gong, J. P. Why are double network hydrogels so tough? Soft Matter 2010, 6, 2583-2590.

(18) Gong, J. P. Materials both tough and soft. Science 2014, 344, $161-162$.

(19) Abandansari, H. S.; Ghanian, M. H.; Varzideh, F.; Mahmoudi, E.; Rajabi, S.; Taheri, P.; Nabid, M. R.; Baharvand, H. In situ formation of interpenetrating polymer network using sequential thermal and click crosslinking for enhanced retention of transplanted cells. Biomaterials 2018, 170, 12-25.

(20) Ngo, T. D.; Kashani, A.; Imbalzano, G.; Nguyen, K. T. Q.; Hui, D. Additive manufacturing (3D printing): A review of materials, methods, applications and challenges. Composites, Part B 2018, 143, $172-196$.

(21) van Kampen, K. A.; Scheuring, R. G.; Terpstra, M. L.; Levato, R.; Groll, J.; Malda, J.; Mota, C.; Moroni, L., Biofabrication: From Additive Manufacturing to Bioprinting. In Reference Module in Biomedical Sciences; Elsevier, 2019.

(22) Moroni, L.; Boland, T.; Burdick, J. A.; De Maria, C.; Derby, B.; Forgacs, G.; Groll, J.; Li, Q.; Malda, J.; Mironov, V. A.; Mota, C.; Nakamura, M.; Shu, W.; Takeuchi, S.; Woodfield, T. B. F.; Xu, T.; Yoo, J. J.; Vozzi, G. Biofabrication: A Guide to Technology and Terminology. Trends Biotechnol. 2018, 36, 384-402.

(23) Pfister, A.; Landers, R.; Laib, A.; Hübner, U.; Schmelzeisen, R.; Mülhaupt, R. Biofunctional rapid prototyping for tissue-engineering applications: 3D bioplotting versus 3D printing. J. Polym. Sci., Part A: Polym. Chem. 2004, 42, 624-638.

(24) Zhu, W.; Ma, X.; Gou, M.; Mei, D.; Zhang, K.; Chen, S. 3D printing of functional biomaterials for tissue engineering. Curr. Opin. Biotechnol. 2016, 40, 103-112.

(25) Lee, A.; Hudson, A. R.; Shiwarski, D. J.; Tashman, J. W.; Hinton, T. J.; Yerneni, S.; Bliley, J. M.; Campbell, P. G.; Feinberg, A.
W. 3D bioprinting of collagen to rebuild components of the human heart. Science 2019, 365, 482-487.

(26) Grigoryan, B.; Paulsen, S. J.; Corbett, D. C.; Sazer, D. W.; Fortin, C. L.; Zaita, A. J.; Greenfield, P. T.; Calafat, N. J.; Gounley, J. P.; Ta, A. H.; Johansson, F.; Randles, A.; Rosenkrantz, J. E.; LouisRosenberg, J. D.; Galie, P. A.; Stevens, K. R.; Miller, J. S. Multivascular networks and functional intravascular topologies within biocompatible hydrogels. Science 2019, 364, 458-464.

(27) Levato, R.; Jungst, T.; Scheuring, R. G.; Blunk, T.; Groll, J.; Malda, J. From Shape to Function: The Next Step in Bioprinting. Adv. Mater. 2020, 32, No. e1906423.

(28) Guvendiren, M.; Molde, J.; Soares, R. M.; Kohn, J. Designing Biomaterials for 3D Printing. ACS Biomater. Sci. Eng. 2016, 2, 16791693.

(29) Malda, J.; Visser, J.; Melchels, F. P.; Jungst, T.; Hennink, W. E.; Dhert, W. J.; Groll, J.; Hutmacher, D. W. 25th anniversary article: Engineering hydrogels for biofabrication. Adv. Mater. 2013, 25, 501128.

(30) Ligon, S. C.; Liska, R.; Stampfl, J.; Gurr, M.; Mulhaupt, R. Polymers for 3D Printing and Customized Additive Manufacturing. Chem. Rev. 2017, 117, 10212-10290.

(31) Kirchmajer, D. M.; Gorkin, R., III; In Het Panhuis, M. An overview of the suitability of hydrogel-forming polymers for extrusionbased 3D-printing. J. Mater. Chem. B 2015, 3, 4105-4117.

(32) Choudhury, D.; Anand, S.; Naing, M. W. The Arrival of Commercial Bioprinters - Towards 3D Bioprinting Revolution! Int. J. Bioprint. 2018, 4, 4.

(33) Jakab, K.; Neagu, A.; Mironov, V.; Markwald, R. R.; Forgacs, G. Engineering biological structures of prescribed shape using selfassembling multicellular systems. Proc. Natl. Acad. Sci. U. S. A. 2004, $101,2864-9$.

(34) Mironov, V.; Boland, T.; Trusk, T.; Forgacs, G.; Markwald, R. $\mathrm{R}$. Organ printing: computer-aided jet-based $3 \mathrm{D}$ tissue engineering. Trends Biotechnol. 2003, 21, 157-161.

(35) Dhariwala, B.; Hunt, E.; Boland, T. Rapid prototyping of tissueengineering constructs, using photopolymerizable hydrogels and stereolithography. Tissue Eng. 2004, 10, 1316-22.

(36) Hribar, K. C.; Soman, P.; Warner, J.; Chung, P.; Chen, S. Lightassisted direct-write of 3D functional biomaterials. Lab Chip 2014, 14 $268-75$.

(37) Hinton, T. J.; Jallerat, Q.; Palchesko, R. N.; Park, J. H.; Grodzicki, M. S.; Shue, H. J.; Ramadan, M. H.; Hudson, A. R.; Feinberg, A. W. Three-dimensional printing of complex biological structures by freeform reversible embedding of suspended hydrogels. Sci. Adv. 2015, 1, No. e1500758.

(38) Highley, C. B.; Rodell, C. B.; Burdick, J. A. Direct 3D Printing of Shear-Thinning Hydrogels into Self-Healing Hydrogels. Adv. Mater. 2015, 27, 5075-5079.

(39) Shusteff, M.; Browar, A. E. M.; Kelly, B. E.; Henriksson, J.; Weisgraber, T. H.; Panas, R. M.; Fang, N. X.; Spadaccini, C. M. Onestep volumetric additive manufacturing of complex polymer structures. Sci. Adv. 2017, 3, No. eaao5496.

(40) Bernal, P. N.; Delrot, P.; Loterie, D.; Li, Y.; Malda, J.; Moser, C.; Levato, R. Volumetric Bioprinting of Complex Living-Tissue Constructs within Seconds. Adv. Mater. 2019, 31, No. e1904209.

(41) Groll, J.; Burdick, J. A.; Cho, D. W.; Derby, B.; Gelinsky, M.; Heilshorn, S. C.; Jungst, T.; Malda, J.; Mironov, V. A.; Nakayama, K.; Ovsianikov, A.; Sun, W.; Takeuchi, S.; Yoo, J. J.; Woodfield, T. B. F. A definition of bioinks and their distinction from biomaterial inks. Biofabrication 2019, 11, 013001.

(42) Li, J.; Wu, C.; Chu, P. K.; Gelinsky, M. 3D printing of hydrogels: Rational design strategies and emerging biomedical applications. Mater. Sci. Eng., R 2020, 140, 100543.

(43) He, Y.; Yang, F.; Zhao, H.; Gao, Q.; Xia, B.; Fu, J. Research on the printability of hydrogels in 3D bioprinting. Sci. Rep. 2016, 6, 29977.

(44) Gopinathan, J.; Noh, I. Recent trends in bioinks for 3D printing. Biomater. Res. 2018, 22, 11. 
(45) Guerra, A. J.; Lammel-Lindemann, J.; Katko, A.; Kleinfehn, A.; Rodriguez, C. A.; Catalani, L. H.; Becker, M. L.; Ciurana, J.; Dean, D. Optimization of photocrosslinkable resin components and 3D printing process parameters. Acta Biomater. 2019, 97, 154-161.

(46) Blaeser, A.; Duarte Campos, D. F.; Puster, U.; Richtering, W.; Stevens, M. M.; Fischer, H. Controlling Shear Stress in 3D Bioprinting is a Key Factor to Balance Printing Resolution and Stem Cell Integrity. Adv. Healthcare Mater. 2016, 5, 326-33.

(47) Ooi, H. W.; Mota, C.; Ten Cate, A. T.; Calore, A.; Moroni, L.; Baker, M. B. Thiol-Ene Alginate Hydrogels as Versatile Bioinks for Bioprinting. Biomacromolecules 2018, 19, 3390-3400.

(48) Bertlein, S.; Brown, G.; Lim, K. S.; Jungst, T.; Boeck, T.; Blunk, T.; Tessmar, J.; Hooper, G. J.; Woodfield, T. B. F.; Groll, J. Thiol-Ene Clickable Gelatin: A Platform Bioink for Multiple 3D Biofabrication Technologies. Adv. Mater. 2017, 29, 1703404.

(49) Hafeez, S.; Ooi, H. W.; Morgan, F. L. C.; Mota, C.; Dettin, M.; Van Blitterswijk, C.; Moroni, L.; Baker, M. B. Viscoelastic Oxidized Alginates with Reversible Imine Type Crosslinks: Self-Healing, Injectable, and Bioprintable Hydrogels. Gels 2018, 4, 85.

(50) Lim, K. S.; Levato, R.; Costa, P. F.; Castilho, M. D.; AlcalaOrozco, C. R.; van Dorenmalen, K. M. A.; Melchels, F. P. W.; Gawlitta, D.; Hooper, G. J.; Malda, J.; Woodfield, T. B. F. Bio-resin for high resolution lithography-based biofabrication of complex cellladen constructs. Biofabrication 2018, 10, 034101.

(51) Dilla, R. A.; Motta, C. M. M.; Snyder, S. R.; Wilson, J. A.; Wesdemiotis, C.; Becker, M. L. Synthesis and 3D Printing of PEGPoly(propylene fumarate) Diblock and Triblock Copolymer Hydrogels. ACS Macro Lett. 2018, 7, 1254-1260.

(52) Liang, K.; Bae, K. H.; Kurisawa, M. Recent advances in the design of injectable hydrogels for stem cell-based therapy. J. Mater. Chem. B 2019, 7, 3775-3791.

(53) Chao, Y.; Chen, Q.; Liu, Z. Smart Injectable Hydrogels for Cancer Immunotherapy. Adv. Funct. Mater. 2020, 30, 1902785.

(54) Fan, D. Y.; Tian, Y.; Liu, Z. J. Injectable Hydrogels for Localized Cancer Therapy. Front. Chem. 2019, 7, 675.

(55) Qu, J.; Zhao, X.; Liang, Y.; Xu, Y.; Ma, P. X.; Guo, B. Degradable conductive injectable hydrogels as novel antibacterial, anti-oxidant wound dressings for wound healing. Chem. Eng. J. 2019, $362,548-560$.

(56) Piantanida, E.; Alonci, G.; Bertucci, A.; De Cola, L. Design of Nanocomposite Injectable Hydrogels for Minimally Invasive Surgery. Acc. Chem. Res. 2019, 52, 2101-2112.

(57) Dimatteo, R.; Darling, N. J.; Segura, T. In situ forming injectable hydrogels for drug delivery and wound repair. Adv. Drug Delivery Rev. 2018, 127, 167-184.

(58) Song, M.; Jang, H.; Lee, J.; Kim, J. H.; Kim, S. H.; Sun, K.; Park, Y. Regeneration of chronic myocardial infarction by injectable hydrogels containing stem cell homing factor SDF-1 and angiogenic peptide Ac-SDKP. Biomaterials 2014, 35, 2436-2445.

(59) Wu, J.; Chen, Q.; Deng, C.; Xu, B.; Zhang, Z.; Yang, Y.; Lu, T. Exquisite design of injectable Hydrogels in Cartilage Repair. Theranostics 2020, 10, 9843-9864.

(60) Seo, B.-B.; Choi, H.; Koh, J.-T.; Song, S.-C. Sustained BMP-2 delivery and injectable bone regeneration using thermosensitive polymeric nanoparticle hydrogel bearing dual interactions with BMP2. J. Controlled Release 2015, 209, 67-76.

(61) Lee, A. S.; Inayathullah, M.; Lijkwan, M. A.; Zhao, X.; Sun, W.; Park, S.; Hong, W. X.; Parekh, M. B.; Malkovskiy, A. V.; Lau, E.; Qin, X.; Pothineni, V. R.; Sanchez-Freire, V.; Zhang, W. Y.; Kooreman, N. G.; Ebert, A. D.; Chan, C. K. F.; Nguyen, P. K.; Rajadas, J.; Wu, J. C. Prolonged survival of transplanted stem cells after ischaemic injury via the slow release of pro-survival peptides from a collagen matrix. Nat. Biomed. Eng. 2018, 2, 104-113.

(62) Ballios, B. G.; Cooke, M. J.; Donaldson, L.; Coles, B. L.K.; Morshead, C. M.; van der Kooy, D.; Shoichet, M. S. A HyaluronanBased Injectable Hydrogel Improves the Survival and Integration of Stem Cell Progeny following Transplantation. Stem Cell Rep. 2015, 4, 1031-1045.
(63) Aguado, B. A.; Mulyasasmita, W.; Su, J.; Lampe, K. J.; Heilshorn, S. C. Improving viability of stem cells during syringe needle flow through the design of hydrogel cell carriers. Tissue Eng., Part A 2012, 18, 806-15.

(64) Dávila, J. L.; d'Ávila, M. A. Rheological evaluation of Laponite/ alginate inks for 3D extrusion-based printing. Int. J. Adv. Manufac. Technol. 2019, 101, 675-686.

(65) Shi, J.; Wu, B.; Li, S.; Song, J.; Song, B.; Lu, W. F. Shear stress analysis and its effects on cell viability and cell proliferation in dropon-demand bioprinting. Biomed. Phys. Eng. Express 2018, 4, 045028.

(66) Hu, X.; Vatankhah-Varnoosfaderani, M.; Zhou, J.; Li, Q.; Sheiko, S. S. Weak hydrogen bonding enables hard, strong, tough, and elastic hydrogels. Adv. Mater. 2015, 27, 6899-6905.

(67) Neal, J. A.; Mozhdehi, D.; Guan, Z. Enhancing mechanical performance of a covalent self-healing material by sacrificial noncovalent bonds. J. Am. Chem. Soc. 2015, 137, 4846-4850.

(68) Dubbin, K.; Tabet, A.; Heilshorn, S. C. Quantitative criteria to benchmark new and existing bio-inks for cell compatibility. Biofabrication 2017, 9, 044102.

(69) Lindsay, C. D.; Roth, J. G.; LeSavage, B. L.; Heilshorn, S. C. Bioprinting of stem cell expansion lattices. Acta Biomater. 2019, 95, $225-235$.

(70) Ouyang, L.; Highley, C. B.; Rodell, C. B.; Sun, W.; Burdick, J. A. 3D printing of shear-thinning hyaluronic acid hydrogels with secondary cross-linking. ACS Biomater. Sci. Eng. 2016, 2, 1743-1751.

(71) Rutz, A. L.; Hyland, K. E.; Jakus, A. E.; Burghardt, W. R.; Shah, R. N. A multimaterial bioink method for 3D printing tunable, cellcompatible hydrogels. Adv. Mater. 2015, 27, 1607-1614.

(72) Rowley, J. A.; Madlambayan, G.; Mooney, D. J. Alginate hydrogels as synthetic extracellular matrix materials. Biomaterials 1999, 20, 45-53.

(73) Sun, J.-Y.; Zhao, X.; Illeperuma, W. R. K.; Chaudhuri, O.; Oh, K. H.; Mooney, D. J.; Vlassak, J. J.; Suo, Z. Highly stretchable and tough hydrogels. Nature 2012, 489, 133-136.

(74) Bakarich, S. E.; Panhuis, M. I. H.; Beirne, S.; Wallace, G. G.; Spinks, G. M. Extrusion printing of ionic-covalent entanglement hydrogels with high toughness. J. Mater. Chem. B 2013, 1, 49394946.

(75) Bakarich, S. E.; Gorkin, R.; Panhuis, M. i. h.; Spinks, G. M. 4D Printing with Mechanically Robust, Thermally Actuating Hydrogels. Macromol. Rapid Commun. 2015, 36, 1211-1217.

(76) Zhou, Y.; Gui, Q.; Yu, W.; Liao, S.; He, Y.; Tao, X.; Yu, Y.; Wang, Y. Interfacial Diffusion Printing: An Efficient Manufacturing Technique for Artificial Tubular Grafts. ACS Biomater. Sci. Eng. 2019, 5, 6311-6318.

(77) Liu, S.; Bastola, A. K.; Li, L. A 3D Printable and Mechanically Robust Hydrogel Based on Alginate and Graphene Oxide. ACS Appl. Mater. Interfaces 2017, 9, 41473-41481.

(78) Belaid, H.; Nagarajan, S.; Teyssier, C.; Barou, C.; Bares, J.; Balme, S.; Garay, H.; Huon, V.; Cornu, D.; Cavailles, V.; Bechelany, M. Development of new biocompatible 3D printed graphene oxidebased scaffolds. Mater. Sci. Eng., C 2020, 110, 110595.

(79) Cai, Y.; Qin, J.; Li, W.; Tyagi, A.; Liu, Z.; Hossain, M. D.; Chen, H.; Kim, J.-K.; Liu, H.; Zhuang, M.; et al. A stretchable, conformable, and biocompatible graphene strain sensor based on a structured hydrogel for clinical application. J. Mater. Chem. A 2019, 7, 2709927109.

(80) Shen, X.; Yang, M.; Cui, C.; Cao, H. In situ immobilization of glucose oxidase and catalase in a hybrid interpenetrating polymer network by 3D bioprinting and its application. Colloids Surf., A 2019, 568, 411-418.

(81) Bootsma, K.; Fitzgerald, M. M.; Free, B.; Dimbath, E.; Conjerti, J.; Reese, G.; Konkolewicz, D.; Berberich, J. A.; Sparks, J. L. 3D printing of an interpenetrating network hydrogel material with tunable viscoelastic properties. J. Mech. Behav. Biomed. Mater. 2017, 70, 8494.

(82) Kuo, C. K.; Ma, P. X. Ionically crosslinked alginate hydrogels as scaffolds for tissue engineering: Part 1 . Structure, gelation rate and mechanical properties. Biomaterials 2001, 22, 511-521. 
(83) Wei, J.; Wang, J.; Su, S.; Wang, S.; Qiu, J.; Zhang, Z.; Christopher, G.; Ning, F.; Cong, W. 3D printing of an extremely tough hydrogel. RSC Adv. 2015, 5, 81324-81329.

(84) Guo, Z.; Xia, J.; Mi, S.; Sun, W. Mussel-Inspired Naturally Derived Double-Network Hydrogels and Their Application in 3D Printing: From Soft, Injectable Bioadhesives to Mechanically Strong Hydrogels. ACS Biomater. Sci. Eng. 2020, 6, 1798-1808.

(85) Trachsel, L.; Johnbosco, C.; Lang, T.; Benetti, E. M.; ZenobiWong, M. Double-Network Hydrogels Including Enzymatically Crosslinked Poly-(2-alkyl-2-oxazoline)s for 3D Bioprinting of Cartilage-Engineering Constructs. Biomacromolecules 2019, 20, $4502-4511$.

(86) Hong, S.; Sycks, D.; Chan, H. F.; Lin, S.; Lopez, G. P.; Guilak, F.; Leong, K. W.; Zhao, X. 3D printing of highly stretchable and tough hydrogels into complex, cellularized structures. Adv. Mater. 2015, 27, 4035-4040.

(87) Colosi, C.; Shin, S. R.; Manoharan, V.; Massa, S.; Costantini, M.; Barbetta, A.; Dokmeci, M. R.; Dentini, M.; Khademhosseini, A. Microfluidic bioprinting of heterogeneous 3D tissue constructs using low-viscosity bioink. Adv. Mater. 2016, 28, 677-684.

(88) Krishnamoorthy, S.; Zhang, Z.; Xu, C. Biofabrication of threedimensional cellular structures based on gelatin methacrylate-alginate interpenetrating network hydrogel. J. Biomater. Appl. 2019, 33, 11051117.

(89) Rhein-Knudsen, N.; Ale, M. T.; Meyer, A. S. Seaweed hydrocolloid production: an update on enzyme assisted extraction and modification technologies. Mar. Drugs 2015, 13, 3340-3359.

(90) Bakarich, S. E.; Gorkin, R.; in het Panhuis, M.; Spinks, G. M. Three-dimensional printing fiber reinforced hydrogel composites. ACS Appl. Mater. Interfaces 2014, 6, 15998-16006.

(91) Liu, S.; Li, L. Ultrastretchable and Self-Healing DoubleNetwork Hydrogel for 3D Printing and Strain Sensor. ACS Appl. Mater. Interfaces 2017, 9, 26429-26437.

(92) Chimene, D.; Miller, L.; Cross, L. M.; Jaiswal, M. K.; Singh, I.; Gaharwar, A. K. Nanoengineered Osteoinductive Bioink for 3D Bioprinting Bone Tissue. ACS Appl. Mater. Interfaces 2020, 12, 15976-15988.

(93) Chimene, D.; Peak, C. W.; Gentry, J. L.; Carrow, J. K.; Cross, L. M.; Mondragon, E.; Cardoso, G. B.; Kaunas, R; Gaharwar, A. K. Nanoengineered Ionic-Covalent Entanglement (NICE) Bioinks for 3D Bioprinting. ACS Appl. Mater. Interfaces 2018, 10, 9957-9968.

(94) Wang, L. L.; Highley, C. B.; Yeh, Y. C.; Galarraga, J. H.; Uman, S.; Burdick, J. A. Three-dimensional extrusion bioprinting of singleand double-network hydrogels containing dynamic covalent crosslinks. J. Biomed. Mater. Res., Part A 2018, 106, 865-875.

(95) Gao, F.; Xu, Z.; Liang, Q.; Li, H.; Peng, L.; Wu, M.; Zhao, X.; Cui, X.; Ruan, C.; Liu, W. Osteochondral Regeneration with 3DPrinted Biodegradable High-Strength Supramolecular Polymer Reinforced-Gelatin Hydrogel Scaffolds. Adv. Sci. 2019, 6, 1900867.

(96) Li, X.; Wang, H.; Li, D.; Long, S.; Zhang, G.; Wu, Z. Dual ionically cross-linked double-network hydrogels with high strength, toughness, swelling resistance, and improved 3D printing Processability. ACS Appl. Mater. Interfaces 2018, 10, 31198-31207.

(97) Li, A.; Si, Y.; Wang, X.; Jia, X.; Guo, X.; Xu, Y. Poly (vinyl alcohol) Nanocrystal-Assisted Hydrogels with High Toughness and Elastic Modulus for Three-Dimensional Printing. ACS Appl. Nano Mater. 2019, 2, 707-715.

(98) Yang, F.; Tadepalli, V.; Wiley, B. J. 3D printing of a double network hydrogel with a compression strength and elastic modulus greater than those of cartilage. ACS Biomater. Sci. Eng. 2017, 3, 863869.

(99) Yang, H.; Li, C.; Yang, M.; Pan, Y.; Yin, Q.; Tang, J.; Qi, H. J.; Suo, Z. Printing hydrogels and elastomers in arbitrary sequence with strong adhesion. Adv. Funct. Mater. 2019, 29, 1901721.

(100) Sultan, S.; Mathew, A. P. 3D printed scaffolds with gradient porosity based on a cellulose nanocrystal hydrogel. Nanoscale 2018, 10, 4421-4431.

(101) Wu, D.; Yu, Y.; Tan, J.; Huang, L.; Luo, B.; Lu, L.; Zhou, C. 3D bioprinting of gellan gum and poly (ethylene glycol) diacrylate based hydrogels to produce human-scale constructs with high-fidelity. Mater. Des. 2018, 160, 486-495.

(102) Guo, J.; Zhang, R.; Zhang, L.; Cao, X. 4D Printing of Robust Hydrogels Consisted of Agarose Nanofibers and Polyacrylamide. ACS Macro Lett. 2018, 7, 442-446.

(103) Darabi, M. A.; Khosrozadeh, A.; Mbeleck, R.; Liu, Y.; Chang, Q.; Jiang, J.; Cai, J.; Wang, Q.; Luo, G.; Xing, M. Skin-Inspired Multifunctional Autonomic-Intrinsic Conductive Self-Healing Hydrogels with Pressure Sensitivity, Stretchability, and 3D Printability. Adv. Mater. 2017, 29 (31), 1700533.

(104) Sharma, A.; Desando, G.; Petretta, M.; Chawla, S.; Bartolotti, I.; Manferdini, C.; Paolella, F.; Gabusi, E.; Trucco, D.; Ghosh, S.; Lisignoli, G. Investigating the Role of Sustained Calcium Release in Silk-Gelatin-Based Three-Dimensional Bioprinted Constructs for Enhancing the Osteogenic Differentiation of Human Bone Marrow Derived Mesenchymal Stromal Cells. ACS Biomater. Sci. Eng. 2019, 5, $1518-1533$

(105) Chen, C. S.; Zeng, F.; Xiao, X.; Wang, Z.; Li, X. L.; Tan, R. W.; Liu, W. Q.; Zhang, Y. S.; She, Z. D.; Li, S. J. Three-Dimensionally Printed Silk-Sericin-Based Hydrogel Scaffold: A Promising Visualized Dressing Material for Real-Time Monitoring of Wounds. ACS Appl. Mater. Interfaces 2018, 10, 33879-33890.

(106) Qiao, Y.; Xu, S.; Zhu, T.; Tang, N.; Bai, X.; Zheng, C. Preparation of printable double-network hydrogels with rapid selfhealing and high elasticity based on hyaluronic acid for controlled drug release. Polymer 2020, 186, 121994.

(107) Rodell, C. B.; Dusaj, N. N.; Highley, C. B.; Burdick, J. A. Injectable and Cytocompatible Tough Double-Network Hydrogels through Tandem Supramolecular and Covalent Crosslinking. Adv. Mater. 2016, 28, 8419-8424.

(108) Sun, Y.; Nan, D.; Jin, H.; Qu, X. Recent advances of injectable hydrogels for drug delivery and tissue engineering applications. Polym. Test. 2020, 81, 106283.

(109) Nguyen, Q. V.; Huynh, D. P.; Park, J. H.; Lee, D. S. Injectable polymeric hydrogels for the delivery of therapeutic agents: A review. Eur. Polym. J. 2015, 72, 602-619.

(110) De France, K. J.; Cranston, E. D.; Hoare, T. Mechanically Reinforced Injectable Hydrogels. ACS Appl. Polym. Mater. 2020, 2, $1016-1030$

(111) Lopez Hernandez, H.; Souza, J. W.; Appel, E. A. A Quantitative Description for Designing the Extrudability of ShearThinning Physical Hydrogels. Macromol. Biosci. 2020, 2000295.

(112) Chee, P. L.; Lakshmanan, L.; Jiang, S.; Ye, H.; Kai, D.; Loh, X. J. An Injectable Double-Network Hydrogel for Cell Encapsulation. Aust. J. Chem. 2016, 69, 388.

(113) Wang, K.; Nune, K. C.; Misra, R. D. The functional response of alginate-gelatin-nanocrystalline cellulose injectable hydrogels toward delivery of cells and bioactive molecules. Acta Biomater. 2016, 36, 143-51.

(114) Bu, Y.; Shen, H.; Yang, F.; Yang, Y.; Wang, X.; Wu, D. Construction of Tough, in Situ Forming Double-Network Hydrogels with Good Biocompatibility. ACS Appl. Mater. Interfaces 2017, 9, 2205-2212.

(115) Yuan, L.; Wu, Y.; Gu, Q. S.; El-Hamshary, H.; El-Newehy, M.; Mo, X. Injectable photo crosslinked enhanced double-network hydrogels from modified sodium alginate and gelatin. Int. J. Biol. Macromol. 2017, 96, 569-577.

(116) Zhou, F.; Hong, Y.; Zhang, X.; Yang, L.; Li, J.; Jiang, D.; Bunpetch, V.; Hu, Y.; Ouyang, H.; Zhang, S. Tough hydrogel with enhanced tissue integration and in situ forming capability for osteochondral defect repair. Appl. Mater. Today 2018, 13, 32-44.

(117) Li, Y.; Yang, L.; Zeng, Y.; Wu, Y.; Wei, Y.; Tao, L. Self-Healing Hydrogel with a Double Dynamic Network Comprising Imine and Borate Ester Linkages. Chem. Mater. 2019, 31, 5576-5583.

(118) Li, L.; Ge, J.; Ma, P. X.; Guo, B. Injectable conducting interpenetrating polymer network hydrogels from gelatin-graftpolyaniline and oxidized dextran with enhanced mechanical properties. RSC Adv. 2015, 5, 92490-92498. 
(119) Wang, L.; Deng, F.; Wang, W.; Li, A.; Lu, C.; Chen, H.; Wu, G.; Nan, K.; Li, L. Construction of Injectable Self-Healing Macroporous Hydrogels via a Template-Free Method for Tissue Engineering and Drug Delivery. ACS Appl. Mater. Interfaces 2018, 10, 36721-36732.

(120) Liu, Z.; Yao, P. Injectable thermo-responsive hydrogel composed of xanthan gum and methylcellulose double networks with shear-thinning property. Carbohydr. Polym. 2015, 132, 490-8.

(121) Cai, L.; Dewi, R. E.; Heilshorn, S. C. Injectable Hydrogels with In Situ Double Network Formation Enhance Retention of Transplanted Stem Cells. Adv. Funct. Mater. 2015, 25, 1344-1351.

(122) Zhao, Y.; Cui, Z.; Liu, B.; Xiang, J.; Qiu, D.; Tian, Y.; Qu, X.; Yang, Z. An Injectable Strong Hydrogel for Bone Reconstruction. Adv. Healthcare Mater. 2019, 8, No. e1900709.

(123) Li, C.; Rowland, M. J.; Shao, Y.; Cao, T.; Chen, C.; Jia, H.; Zhou, X.; Yang, Z.; Scherman, O. A.; Liu, D. Responsive Double Network Hydrogels of Interpenetrating DNA and CB[8] Host-Guest Supramolecular Systems. Adv. Mater. 2015, 27, 3298-304.

(124) Yan, Y.; Li, M.; Yang, D.; Wang, Q.; Liang, F.; Qu, X.; Qiu, D.; Yang, Z. Construction of Injectable Double-Network Hydrogels for Cell Delivery. Biomacromolecules 2017, 18, 2128-2138.

(125) Yang, C.; Han, B.; Cao, C.; Yang, D.; Qu, X.; Wang, X. An injectable double-network hydrogel for the co-culture of vascular endothelial cells and bone marrow mesenchymal stem cells for simultaneously enhancing vascularization and osteogenesis. J. Mater. Chem. B 2018, 6, 7811-7821.

(126) Wang, H.; Zhu, D.; Paul, A.; Cai, L.; Enejder, A.; Yang, F.; Heilshorn, S. C. Covalently Adaptable Elastin-Like Protein-Hyaluronic Acid (ELP-HA) Hybrid Hydrogels with Secondary Thermoresponsive Crosslinking for Injectable Stem Cell Delivery. Adv. Funct. Mater. 2017, 27, 1605609.

(127) Cho, I. S.; Ooya, T. Tuned cell attachments by doublenetwork hydrogels consisting of glycol chitosan, carboxylmethyl cellulose and agar bearing robust and self-healing properties. Int. J. Biol. Macromol. 2019, 134, 262-268.

(128) Qu, J.; Zhao, X.; Liang, Y.; Zhang, T.; Ma, P. X.; Guo, B. Antibacterial adhesive injectable hydrogels with rapid self-healing, extensibility and compressibility as wound dressing for joints skin wound healing. Biomaterials 2018, 183, 185-199.

(129) Guo, Z.; Gu, H.; He, Y.; Zhang, Y.; Xu, W.; Zhang, J.; Liu, Y.; Xiong, L.; Chen, A.; Feng, Y. Dual dynamic bonds enable biocompatible and tough hydrogels with fast self-recoverable, selfhealable and injectable properties. Chem. Eng. J. 2020, 388, 124282.

(130) Wang, D.; Xia, Y.; Zhang, D.; Sun, X.; Chen, X.; Oliver, S.; Shi, S.; Lei, L. Hydrogen-Bonding Reinforced Injectable Hydrogels: Application As a Thermo-Triggered Drug Controlled-Release System. ACS Appl. Polym. Mater. 2020, 2, 1587-1596.

(131) Zhang, Y.; Heher, P.; Hilborn, J.; Redl, H.; Ossipov, D. A. Hyaluronic acid-fibrin interpenetrating double network hydrogel prepared in situ by orthogonal disulfide cross-linking reaction for biomedical applications. Acta Biomater. 2016, 38, 23-32.

(132) Li, H.; Liu, F.; Li, Z.; Wang, S.; Jin, R.; Liu, C.; Chen, Y. Fingerprintable Hydrogel from Dual Reversible Cross-Linking Networks with Different Relaxation Times. ACS Appl. Mater. Interfaces 2019, 11, 17925-17930.

(133) Liu, K.; Zang, S.; Xue, R.; Yang, J.; Wang, L.; Huang, J.; Yan, Y. Coordination-Triggered Hierarchical Folate/Zinc Supramolecular Hydrogels Leading to Printable Biomaterials. ACS Appl. Mater. Interfaces 2018, 10, 4530-4539.

(134) Zhu, K.; Chen, N.; Liu, X.; Mu, X.; Zhang, W.; Wang, C.; Zhang, Y. S. A General Strategy for Extrusion Bioprinting of BioMacromolecular Bioinks through Alginate-Templated Dual-Stage Crosslinking. Macromol. Biosci. 2018, 18, 1800127.

(135) Ghanian, M. H.; Mirzadeh, H.; Baharvand, H. In Situ Forming, Cytocompatible, and Self-Recoverable Tough Hydrogels Based on Dual Ionic and Click Cross-Linked Alginate. Biomacromolecules 2018, 19, 1646-1662. 